\title{
Combined preliminary-detailed design of wind turbines
}

\author{
Pietro Bortolotti ${ }^{1}$, Carlo L. Bottasso ${ }^{1,2}$, and Alessandro Croce $^{2}$ \\ ${ }^{1}$ Wind Energy Institute, Technische Universität München, 85748 Garching b. München, Germany \\ ${ }^{2}$ Dipartimento di Scienze e Tecnologie Aerospaziali, Politecnico di Milano, 20156 Milan, Italy \\ Correspondence to: Carlo L. Bottasso (carlo.bottasso@tum.de)
}

Received: 17 December 2015 - Published in Wind Energ. Sci. Discuss.: 21 January 2016

Accepted: 18 April 2016 - Published: 30 May 2016

\begin{abstract}
This paper is concerned with the holistic optimization of wind turbines. A multi-disciplinary optimization procedure is presented that marries the overall sizing of the machine in terms of rotor diameter and tower height (often termed "preliminary design") with the detailed sizing of its aerodynamic and structural components. The proposed combined preliminary-detailed approach sizes the overall machine while taking into full account the subtle and complicated couplings that arise due to the mutual effects of aerodynamic and structural choices. Since controls play a central role in dictating performance and loads, control laws are also updated accordingly during optimization. As part of the approach, rotor and tower are sized simultaneously, even in this case capturing the mutual effects of one component over the other due to the tip clearance constraint. The procedure, here driven by detailed models of the cost of energy, results in a complete aero-structural design of the machine, including its associated control laws.

The proposed methods are tested on the redesign of two wind turbines, a $2.2 \mathrm{MW}$ onshore machine and a large $10 \mathrm{MW}$ offshore one. In both cases, the optimization leads to significant changes with respect to the initial baseline configurations, with noticeable reductions in the cost of energy. The novel procedures are also exercised on the design of low-induction rotors for both considered wind turbines, showing that they are typically not competitive with conventional high-efficiency rotors.
\end{abstract}

\section{Introduction}

The size of wind turbines has been steadily growing over the last three decades, following a continuous technological trend aiming at better performance and lower costs. Numerous areas of research and development have been involved in this process, such as rotor aerodynamics, rotor and tower structural design and manufacturing, active and passive load reduction techniques, sensing and advanced control strategies, electromechanical conversion, material technology, and many others. Overall, a very significant body of technological improvements has been proposed and developed over the years, the most successful having been slowly but continuously integrated into commercial machines.

In this context, design has the crucial role of evaluating the various technologies and their influence on the final outcome. In fact, as all innovations will come at a cost (in terms of manufacturing, maintenance, availability, etc.), it is only through the holistic view of design that one can judge whether the benefits offered by a new solution offset their inevitable drawbacks or not. To achieve the goal of designing better machines, there is then a need to develop reliable and comprehensive multi-disciplinary design tools. Such tools, invariably based on suitable simulation models, should be able to describe to a sufficient level of fidelity all the relevant physics, and should capture the important couplings among all involved subdisciplines. In this multi-disciplinary optimization challenge, the most suitable merit figure driving design optimization is often found to be the cost of energy (CoE) (Ning et al., 2013).

Besides being a complex multi-physics problem, a second challenge of wind turbine design is represented by the different operating conditions that a wind turbine encounters throughout its lifetime, a concept currently being translated by standard certification guidelines into the definition of a comprehensive set of design load cases (DLCs). This read- 
ily excludes the possibility of a monolithic brute-force optimization approach to the design task, and in turn requires more complex algorithmic structures. Over the years, several research groups have risen to the challenge of addressing this goal by following different approaches. Most of these studies initially focused on the sole blade design problem, as, for example, in Maalawi and Badr (2003), Jureczko and Pawlak (2005), and Xudong et al. (2009). Integrated tools appeared later, leading to the development of the packages FOCUS from the Energy Research Centre of the Netherlands (ECN) (Duineveld, 2008), HAWTOPT from Danmarks Tekniske Universitet (DTU) (Døssing, 2011) and WISDEM from the National Renewable Energy Laboratory (NREL) and Sandia National Laboratories in the USA (Dykes et al., 2014). In parallel, the multi-disciplinary research code $\mathrm{Cp}-\mathrm{Max}$ (Code for Performance Maximization) was developed integrating a high-fidelity aeroelastic simulator together with optimization algorithms, here again evolving from a mostly structural sizing code to a more comprehensive optimization environment (Bottasso et al., 2011, 2013, 2015). More recently, other studies followed a multi-level approach to wind turbine design, but with the same focus of achieving a $\mathrm{CoE}$ reduction (Maki et al., 2012; Ashuri et al., 2014).

A distinction is often made between conceptual (or preliminary) and detailed design. In the former case, one typically uses reduced-order models (often in the form of look-up tables, regressions of historical data, analytical low-fidelity models, etc.) in order to identify some macro-parameters of a system, such as, in the present context, the rated power, rotor radius, and tower height. This initial preliminary design stage is then followed by a detailed design step. In this second phase, one is concerned with the actual optimal sizing of the various aspects of the system, while keeping the macroparameters fixed. In the present context, this means, for example, finding the optimal aerodynamic shape of the blade, and performing the associated optimal structural sizing. This two-step process, which clearly can be iterated, works reasonably well in practice, and in fact it is at the basis of classical airplane design methods that are well rooted in the history of aviation (Roskam, 2003; Raymer, 2012).

However, this distinction is artificial, and the time is ripe for its elimination. In fact, all aspects, disciplines and systems of a wind turbine are so intimately connected that choosing some important parameters based on simplified methods invariably leads to the risk of missing potentially important effects. For example, changing the rotor diameter has dramatic impacts on the aerodynamics (and hence power performance of the machine), loads (and hence structural sizing, controls, aeroelasticity, subsystems, etc.), transportation, manufacturing, and other aspects. It is extremely difficult, if not impossible, to accurately account for all these effects without modeling the underlying physical processes. For these reasons, it is important to develop methods that can choose the macroscopic configuration of a machine, taking into full account the effects that these choices imply also at the level of its detailed sizing.

This paper aims at proposing new comprehensive wind turbine design methodologies by including some macroparameters such as rotor radius and hub height in the optimization algorithm while retaining the ability to simultaneously perform a detailed sizing of the machine aerodynamics and structures, together with their associated control laws. To keep the computational effort within the limits of typical industrial practice, where one should be able to deliver a new design configuration in a matter of hours or tens of hours, the code implements a new nested architecture of the optimization algorithm. This novel implementation of the code represents a marriage between preliminary and detailed designs, to the benefit of the overall optimization process.

This paper is organized according to the following plan. Section 2 describes the design methodology, with a brief review of the characteristics of the aeroelastic simulation code reported in Sect. 2.1, a detailed description of the architecture and algorithmic flow of the proposed procedures in Sect. 2.2, and finally a brief overview of the cost models used for driving the optimization in Sect. 2.3. Then, Sect. 3 reports on the application of the new methods to a commercial scale 2.2 MW onshore wind turbine, reported in Sect. 3.1, and a conceptual $10 \mathrm{MW}$ offshore wind turbine, described in Sect. 3.2. The paper is closed by Sect. 4, where conclusions are reported and plans for future work are sketched.

\section{Design methods}

\subsection{Aeroservoelastic simulator}

The core of any wind turbine design tool is a simulation model, which must be able to represent with sufficient accuracy the static and dynamic behavior of the machine under all relevant conditions experienced throughout its lifetime. The aeroservoelastic multibody-based code $\mathrm{Cp}$-Lambda (Code for Performance, Loads, Aeroelasticity by Multi-Body Dynamic Analysis) is used in this study. The code, originally developed for rotorcraft applications, is based on Cartesian coordinates and scaled Lagrange multipliers for the enforcement of constraints, while it performs the forward time integration by an implicit nonlinearly unconditionally stable energy decaying scheme. $\mathrm{Cp}$-Lambda implements a complete library of elements, including nonlinear flexible compositeready beams, rigid bodies, joints, actuators and sensors. The code is tightly coupled with aerodynamic models based on the classical blade-element momentum (BEM) approach, formulated according to the annular stream-tube theory with wake swirl, including tip and hub loss models, as well as unsteady corrections and dynamic stall. Cp-Lambda implements the design guidelines prescribed by international certification standards (International Electrotechnical Commission, 2005; Germanischer Lloyd, 2010). Turbulent wind time histories are generated with the open-source code TurbSim 
(Jonkman and Kilcher, 2012), while deterministic gusts are generated according to international standards.

$\mathrm{Cp}$-Lambda has been used in several industrial and research projects, and it has been validated against industrial simulation programs, wind tunnel experimental results and field measurements. Readers interested in the mathematical formulation of $\mathrm{Cp}$-Lambda can refer to Bauchau et al. (2003), Bottasso et al. (2006), Bauchau et al. (2009), and Bauchau (2011), while wind turbine applications of the code can be found among others in Bottasso et al. (2011, 2015).

The wind turbine model is interfaced with an external routine, implementing the necessary supervision and control strategies. In the current study, the linear quadratic regulator (LQR) described in Bottasso et al. (2012) was used. This model-based formulation allows for a straightforward update of the control laws during design, as its underlying reduced-order model can be readily updated whenever the wind turbine parameters change, thereby automatically producing new sets of gains that work in combination with the new design. While probably not superior to other classical pitch-torque controllers used in industrial practice, this method was found to be useful in a design context, as it simplifies the problem of automatically generating control laws of good performance that are capable of following the evolution of a wind turbine during design optimization.

\subsection{Wind turbine design algorithm}

$\mathrm{Cp}-\mathrm{Max}$ is a wind turbine design tool wrapped around $\mathrm{Cp}-\mathrm{Lambda}$, and its latest architecture is presented in the following. The code was first implemented as an aerodynamic optimization tool for blade chord and twist distributions aiming at a maximization of the annual energy production (AEP) for a given wind turbine macro-configuration. The procedures soon also included a purely structural optimization package for the blade (Bottasso et al., 2011), whose merit figure was the minimization of rotor mass. This was achieved by coupling $\mathrm{Cp}$-Lambda with the finite element cross sectional analysis code ANBA (ANisotropic Beam Analysis), implementing the theory of Giavotto et al. (1983). Given airfoils, blade topology, composite mechanical properties and the geometry of the cross section structural members, ANBA produces the six-by-six stiffness matrix that defines the sectional characteristics at a given spanwise location of the geometrically exact shear and torsion-deformable beam model used in $\mathrm{Cp}$-Lambda. The procedure allows one to model the effects of anisotropic composite materials, for example by exploiting the couplings induced by the proper orientation of unidirectional laminates to obtain bend-twist coupling effects in blades, as, for example, demonstrated in Bottasso et al. (2013). A similar procedure also allows for the structural sizing of the wind turbine tower, which can optionally be dimensioned simultaneously to the rotor (Bottasso et al., 2014a).
Because of the very definition of a beam and a beam cross section, none of these models is capable of capturing threedimensional effects in regions of very rapid changes or discontinuity in the structural geometry and/or material properties, as, for example, at stations where shear webs begin or end. To address this intrinsic limitation of combined sectional/beam models, the code was equipped with a multilevel approach, whereby a detailed finite element method (FEM) model of the blade is used to capture the threedimensional state of stress and strain to a higher level of precision. Iterations between the sectional aeroservoelastic and FEM levels are used to ensure that all desired structural constraints (as the satisfaction of allowables, fatigue, buckling, etc.) are verified at the fine FEM level by means of static, modal and fatigue analyses. As more fully described in Bottasso et al. (2014a), the FEM-level analyses are conducted by using loads computed at the aeroservoelastic level, and results of such analyses are used for updating the bounds of design constraints at the next iteration.

A further expansion of the wind turbine design methodology was finally reached when ad hoc algorithms were formulated to simultaneously optimize blade aerodynamics and structure. This offered the opportunity to perform a truly integrated aero-structural rotor optimization (Bottasso et al., 2015).

However, this version of $\mathrm{Cp}-\mathrm{Max}$ represented a detailed design tool that lacked the ability to directly modify the macroscopic configurational parameters of the wind turbine. Extensive use of the software highlighted a general weak sensitivity of the CoE merit figure to the blade aerodynamic and structural design parameters at frozen global wind turbine configuration, i.e. at fixed rotor diameter and tower height. In other words, while changes in the details of the blade aerodynamic shape and structural components significantly affect AEP, mass, loads, etc., in reality CoE often appeared to be significantly flat around an optimum.

The present paper aims at developing procedures for a more extensive exploration of the design space, through a global redesign activity of the wind turbine. This is achieved by including in the optimization process macro-parameters that are typically associated with a preliminary design phase. However, differently from simpler approaches, the inclusion of macro-parameters in the optimization is done here while retaining the ability to perform a multi-level aero-structural design of the rotor (and optionally of the tower), achieving in this way the marriage between the preliminary and detailed design phases. This is done with the goal of also capturing the effects of the detailed design features at the level of the macro-design parameters, avoiding simplifications and the danger of missing important couplings.

The overall architecture of the resulting multi-level combined preliminary-detailed design procedures, as more precisely described later on in the following pages and in Bottasso et al. (2011, 2014a, 2015), is shown in Fig. 1. 


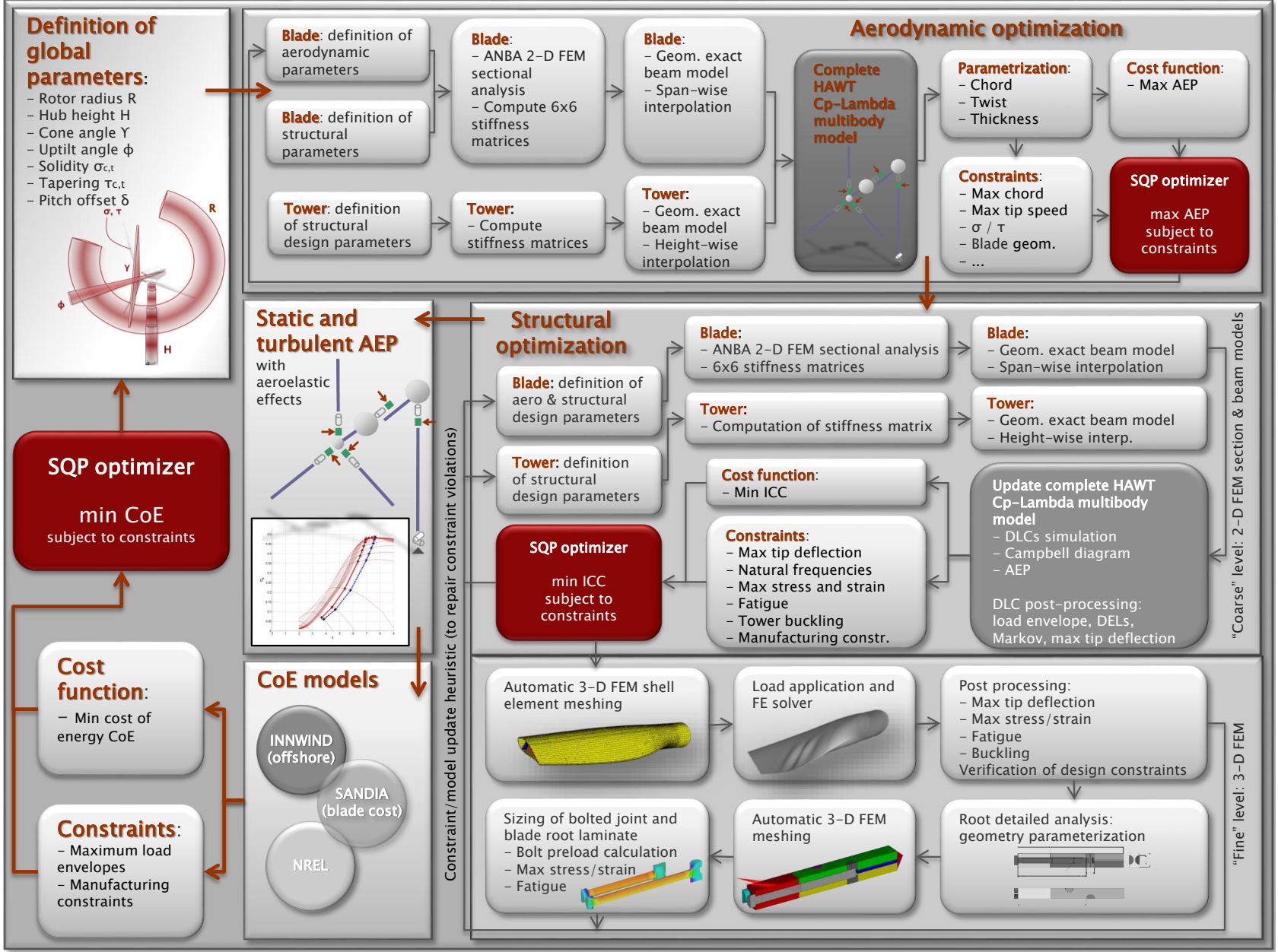

Figure 1. Overall architecture of the multi-level combined preliminary-detailed design procedure.

The rest of this discussion is organized as follows. First, the aerodynamic optimization algorithm is briefly presented in Sect. 2.2.1. Then, a short summary of the structural optimization is reported in Sect. 2.2.2. The proposed nested structure of the combined preliminary-detailed algorithm is finally presented in Sect. 2.2.3. In addition, Chaviaropoulos and Sieros (2014) highlighted the potential benefits of low-induction rotors (LIRs). A way to accommodate the design of such rotors in the current framework is discussed in Sect. 2.2.4.

In the following sections, for clarity of the formulation, a formal description of the structure of the algorithms is given. To this end, functions are indicated with the notation

$(O)=$ FunctionName $(I)$,

where $I$ are the input variables and $O$ the output ones.

\subsubsection{Aerodynamic optimization}

The aerodynamic optimization function, described in detail in Bottasso et al. (2015), is here only briefly recalled with the following formal description:

Function $\left(\boldsymbol{p}_{\mathrm{a}}^{*}, \mathrm{AEP}^{*}\right)=\operatorname{MaxAEP}\left(\boldsymbol{p}_{\mathrm{a}}, \boldsymbol{p}_{\mathrm{s}}, \boldsymbol{p}_{\mathrm{g}}, D\right)$ :

$\boldsymbol{p}_{\mathrm{a}}=\boldsymbol{p}_{\mathrm{a}_{\mathrm{c}}} \cup \boldsymbol{p}_{\mathrm{a}_{\theta}} \cup \boldsymbol{p}_{\mathrm{at}_{\mathrm{t}}}$,

$\mathrm{AEP}^{*}=\max _{\boldsymbol{p}_{\mathrm{a}}}\left(\right.$ ComputeAEP $\left.\left(\boldsymbol{p}_{\mathrm{a}}, \boldsymbol{p}_{\mathrm{s}}, \boldsymbol{p}_{\mathrm{g}}, D\right)\right)$

$\left(\right.$ and $\boldsymbol{p}_{\mathrm{a}}^{*}=\arg \left(\max _{\boldsymbol{p}_{\mathrm{a}}}(\right.$ ComputeAEP $\left.\left.)\right)\right)$,

such that $\boldsymbol{g}_{\mathrm{a}}\left(\boldsymbol{p}_{\mathrm{a}}\right) \leq \mathbf{0}$,

where $\boldsymbol{p}_{\mathrm{a}}, \boldsymbol{p}_{\mathrm{s}}$ and $\boldsymbol{p}_{\mathrm{g}}$ are vector arrays containing, respectively, the aerodynamic, structural and global variables of the optimization problem. Function MaxAEP optimizes $\boldsymbol{p}_{\mathrm{a}}$, while $\boldsymbol{p}_{\mathrm{s}}$ and $\boldsymbol{p}_{\mathrm{g}}$ are respectively controlled by Eq. (4), described in Sect. 2.2.2, and by Eq. (5), described in Sect. 2.2.3. As shown in Eq. (2b), $\boldsymbol{p}_{\mathrm{a}}$ includes the three vectors $\boldsymbol{p}_{\mathrm{a}_{\mathrm{c}}}$, $\boldsymbol{p}_{\mathrm{a}_{\theta}}$ and $\boldsymbol{p}_{\mathrm{a}_{\mathrm{t}}}$ containing discrete nodal parameters that control chord, twist and thickness distributions, respectively, obtained by spline interpolation. The thickness distribution described by $\boldsymbol{p}_{\mathrm{a}_{\mathrm{t}}}$ is obtained by interpolating the thicknesses of a given number of chosen airfoils; by controlling their span- 
wise position, one in turn may affect the local thickness of the blade. Finally, $D$ is a list of given input data:

$D=\left\{P_{\mathrm{r}}, C, V_{\text {in }}, V_{\text {out }}, \mathrm{AF}, v_{\text {tip }_{\max }}, L_{\mathrm{DLC}}, \ldots\right\}$.

The list includes all the quantities that remain constant through the different optimization loops, such as generator rated power $P_{\mathrm{r}}$, wind turbine class $C$, cut-in $V_{\text {in }}$ and cut-out $V_{\text {out }}$ wind speeds, blade airfoil family AF, maximum allowable tip speed $v_{\text {tip }}$ ax and the list $L_{\mathrm{DLC}}=\{\ldots, \mathrm{DLC} i . j, \ldots\}$ containing all the DLCs (International Electrotechnical Commission, 2005; Germanischer Lloyd, 2010) that one may want to consider in the optimization of the machine.

Goal of the aerodynamic optimization is to achieve the highest annual energy production, whose optimum value is noted AEP* in Eq. (2c), while respecting the nonlinear constraints $\boldsymbol{g}_{\mathrm{a}}\left(\boldsymbol{p}_{\mathrm{a}}\right)$ expressed by Eq. (2d). At this stage, AEP is preliminary calculated for each instantiation of the design parameters $\boldsymbol{p}_{\mathrm{a}}$ by integrating the product of the power curve with the Weibull wind distribution for the given class $C$; however, AEP is later on recomputed using turbulent aeroelastic simulations, as also shown in Fig. 1. The vector of conditions $\boldsymbol{g}_{\mathrm{a}}$ can be tailored based on design needs, and it typically includes limits on the maximum allowable tip speed, maximum chord, upper and lower bounds on solidity and tapering for chord and thickness distributions, as well as limitations to the twist distribution in order to take into account manufacturing constraints. The constrained optimization problem is solved by means of a sequential quadratic programming (SQP) algorithm, where gradients are computed by means of forward finite differences. The optimal parameters solving this problem are indicated as $\boldsymbol{p}_{\mathrm{a}}^{*}$ in correspondence to the optimum cost AEP*, as shown in Eq. (2c).

\subsubsection{Structural optimization}

The structural optimization procedure, described in detail in Bottasso et al. (2011), is a more complex and computationally expensive loop that aims at identifying the set of parameters $\boldsymbol{p}_{\mathrm{s}}^{*}$, which describe blade and tower structure at frozen rotor shape, associated with the minimum initial capital cost ICC ${ }^{*} \boldsymbol{p}_{\mathrm{s}}$ is a vector containing the thickness of the structural components at selected stations along the blades, such as spar caps, skin, shear webs and reinforcements; for the tower, this vector contains the outer diameters and wall thicknesses at selected stations along its height. The corresponding distributions are obtained by spline interpolations of these nodal values placed at user-defined stations. The formal description of the algorithm is as follows:
Function $\left(\boldsymbol{p}_{\mathrm{s}}^{*}, \mathrm{ICC}^{*}\right)=\operatorname{MinICC}\left(\boldsymbol{p}_{\mathrm{a}}, \boldsymbol{p}_{\mathrm{s}}, \boldsymbol{p}_{\mathrm{g}}, D, \boldsymbol{\Gamma}_{\mathrm{s}}\right)$ :

do

$(\mathrm{LQR})=\mathrm{LQRController}\left(\boldsymbol{p}_{\mathrm{a}}, \boldsymbol{p}_{\mathrm{s}}, \boldsymbol{p}_{\mathrm{g}}, D\right)$,

$(\boldsymbol{E})=$ LoadEnvelope $\left(\boldsymbol{p}_{\mathrm{a}}, \boldsymbol{p}_{\mathrm{s}}, \boldsymbol{p}_{\mathrm{g}}, D, \mathrm{LQR}\right)$,

$\mathrm{ICC}^{*}=\min _{\boldsymbol{p}_{\mathrm{s}}}\left(\right.$ ComputeICC $\left.\left(\boldsymbol{p}_{\mathrm{a}}, \boldsymbol{p}_{\mathrm{s}}, \boldsymbol{p}_{\mathrm{g}}, D, \boldsymbol{E}, \boldsymbol{\Gamma}_{\mathrm{s}}\right)\right)$,

$$
\left(\text { and } \boldsymbol{p}_{\mathrm{s}}^{*}=\arg \left(\min _{\boldsymbol{p}_{\mathrm{s}}}(\text { ComputeICC })\right)\right) \text {, }
$$

$\left(\boldsymbol{\Gamma}_{\mathrm{s}}^{*}\right)=3$ DFEAnalysis $\left(\boldsymbol{p}_{\mathrm{a}}, \boldsymbol{p}_{\mathrm{s}}^{*}, \boldsymbol{p}_{\mathrm{g}}, D, \boldsymbol{E}, \boldsymbol{\Gamma}_{\mathrm{s}}\right)$,

$\Delta p_{\mathrm{s}}=\left\|\boldsymbol{p}_{\mathrm{s}}^{*}-\boldsymbol{p}_{\mathrm{s}}\right\|, \Delta \mathrm{ICC}=\left\|\mathrm{ICC}^{*}-\mathrm{ICC}\right\|$,

$\Delta \Gamma_{\mathrm{s}}=\left\|\boldsymbol{\Gamma}_{\mathrm{s}}^{*}-\boldsymbol{\Gamma}_{\mathrm{s}}\right\|$,

$\boldsymbol{p}_{\mathrm{s}}=\boldsymbol{p}_{\mathrm{s}}^{*}, \boldsymbol{\Gamma}_{\mathrm{s}}=\Gamma_{\mathrm{s}}^{*}$

while $\left(\Delta p_{\mathrm{s}} \geq \operatorname{tol}_{p_{\mathrm{s}}}, \quad \Delta \mathrm{ICC} \geq \operatorname{tol}_{\mathrm{ICC}}, \quad \Delta \Gamma_{\mathrm{s}} \geq \operatorname{tol}_{\Gamma_{\mathrm{s}}}\right)$.

The structural optimization is an iterative loop, beginning in Eq. (4c) with the calculation of the regulation trajectory and the synthesis of the LQR controller gains, which are updated based on the current wind turbine design (Bottasso et al., 2012). Next, a load computation step is performed, as expressed by Eq. (4d), where DLCs from the list $L_{\text {DLC }}$ in Eq. (3) are run by using the simulation model (in the present case, implemented in $\mathrm{Cp}$-Lambda). The post-processed results of these analyses are used to compute the load envelopes $\boldsymbol{E}$ at a number of verification stations along blades and tower. The rainflow counting required to estimate fatigue damage is also performed here.

This step is followed by a rotor and tower structural sizing for the given load envelopes $\boldsymbol{E}$, as expressed by Eq. (4e). In this second step, the minimum initial capital cost ICC ${ }^{*}$ is computed, together with its associated optimal set of design variables $\boldsymbol{p}_{\mathrm{s}}^{*}$. The inputs to ComputeICC are the aerodynamic, structural and global parameters $\boldsymbol{p}_{\mathrm{a}}, \boldsymbol{p}_{\mathrm{s}}$ and $\boldsymbol{p}_{\mathrm{g}}$, respectively; the input list $D$; the load envelopes $\boldsymbol{E}$ at the verification stations; and finally a list of parameters $\boldsymbol{\Gamma}_{\mathrm{S}}$ used to impose desired design requirements. $\boldsymbol{\Gamma}_{\mathrm{s}}$ includes the admissible values for stress and strain, frequency constraints, buckling constraints for sandwich core sizing and the maximum allowable blade tip deflection based on tower clearance (updated based on the current geometry of the machine and the tower). As for the maximum of ComputeAEP, the minimum of Compute ICC is also solved by means of a SQP optimization algorithm, which is well suited to problems with several constraints that are potentially simultaneously active at convergence. Here again, gradients are computed by means of forward finite differences.

The structural sizing of ComputeICC is followed by Eq. (4f), which represents a higher-fidelity 3-D FEM analysis, whose role is to verify the fulfillment of all the structural constraints at a finer description level by updating, when necessary, vector $\boldsymbol{\Gamma}_{\mathrm{s}}$ into $\boldsymbol{\Gamma}_{\mathrm{s}}^{*}$ (Bottasso et al., 2014a). Given inner 
and outer blade geometry, a 3-D shell-element mesh of the blade is created and associated with a set of load conditions.

Thicknesses are treated as continuous variables in ComputeICC, although in reality laminates are made of an integer number of plies. This is done to avoid the need to use mixed integer programming techniques to handle discrete variables. To correct for this, continuous thicknesses are translated into discrete ones at the exit of ComputeICC, so that all the resulting information, including the FEM model, beam stiffnesses at the next iterations, etc., account for this correction. Typically, as thicknesses in large blades are significant and imply a relatively large number of plies, differences between the continuous and discrete values are small and cause only limited corrections to the models.

Load conditions are obtained by post-processing the outputs of the aeroservoelastic simulation of all considered DLCs, selecting those loads that induce extreme stress and strain values, loads associated with maximum tip deflections, and time histories of the turbulent load cases for the evaluation of fatigue damage. For each loading condition, spanwise distributions of the internal stress resultants and of the aerodynamic forces are readily available from the multibody simulations. These are used for computing equivalent loads that are then applied to the FEM model to achieve realistic loading conditions for each blade component, e.g. by limiting the application of the aerodynamic loads to the external skin nodes. The FEM input model is then fed to the commercial FEM solver NASTRAN (MSC Software, 2012), which is in turn coupled to an automated post-processing routine that closes the loop.

Function 3DFEAnalaysis is generally found to produce changes in the constraint bounds $\boldsymbol{\Gamma}_{\mathrm{s}}$ for the blade root design, for the detailed sandwich core sizing and in the presence of large 3-D effects, such as blade regions with strong transitions in chord size or at the beginning and end of the shear webs. On the other hand, most of the other blade components are generally well sized by the analysis performed at the beam and sectional levels in Eq. (4e). In this sense, ICC is often not largely affected by Eq. (4f).

Overall, the structural loop of Eq. (4) converges when $\boldsymbol{p}_{\mathrm{s}}$, ICC and $\boldsymbol{\Gamma}_{\mathrm{s}}$ are within a predefined tolerance, as reported in Eq. (4i).

\subsubsection{Overall integrated sizing}

The aero-structural optimization is an outer loop that integrates together the aerodynamic optimization, the structural optimization and the CoE evaluation. Its goal is to find the optimal vector $\boldsymbol{p}_{\mathrm{g}}^{*}$, and the associated aerodynamic and structural vectors $\boldsymbol{p}_{\mathrm{a}}^{*}$ and $\boldsymbol{p}_{\mathrm{s}}^{*}$, that achieves a minimum cost of energy $\mathrm{CoE}^{*}$. The algorithm can be formally described as

$$
\begin{aligned}
& \text { Function }\left(\boldsymbol{p}_{\mathrm{a}}^{*}, \boldsymbol{p}_{\mathrm{s}}^{*}, \boldsymbol{p}_{\mathrm{g}}^{*}, \mathrm{CoE}^{*}\right)= \\
& \qquad \operatorname{MinCoE}\left(\boldsymbol{p}_{\mathrm{a}}, \boldsymbol{p}_{\mathrm{s}}, \boldsymbol{p}_{\mathrm{g}}, D, \boldsymbol{\Gamma}_{\mathrm{s}}\right): \\
& \mathrm{CoE}^{*}=\min _{\boldsymbol{p}_{\mathrm{g}}}\left(\operatorname{ComputeCoE}\left(\boldsymbol{p}_{\mathrm{a}}, \boldsymbol{p}_{\mathrm{s}}, \boldsymbol{p}_{\mathrm{g}}, D, \boldsymbol{\Gamma}_{\mathrm{s}}\right)\right), \\
& \left(\operatorname{and}\left(\boldsymbol{p}_{\mathrm{a}}^{*}, \boldsymbol{p}_{\mathrm{s}}^{*}, \boldsymbol{p}_{\mathrm{g}}^{*}\right)=\arg \left(\min _{\boldsymbol{p}_{\mathrm{g}}}(\operatorname{ComputeCoE})\right)\right),
\end{aligned}
$$$$
\text { such that } \boldsymbol{g}_{\mathrm{g}}\left(\boldsymbol{p}_{\mathrm{g}}\right) \leq 0 \text {. }
$$

The vector of global optimization variables $\boldsymbol{p}_{\mathrm{g}}$ is defined as

$\boldsymbol{p}_{\mathrm{g}}=\left[R, H, \gamma, \phi, \sigma_{\mathrm{c}}, \tau_{\mathrm{c}}, \sigma_{\mathrm{t}}, \tau_{\mathrm{t}}\right]$,

where the symbols indicate the rotor radius $R$; hub height $H$; rotor cone angle $\gamma$; nacelle uptilt angle $\phi$; and four blade aero-structural terms $\sigma_{\mathrm{c}}, \tau_{\mathrm{c}}, \sigma_{\mathrm{t}}$ and $\tau_{\mathrm{t}}$. The rotor radius $R$ directly influences the length of the blades, causing cascade changes in the aerodynamic performance of the machine, in its regulation trajectory as well as in the loads. Moreover, $R$ is a scaling factor for cost items within the CoE models, for instance the pitch system cost. As a result, the CoE merit figure has the highest sensitivity with respect to $R$.

IEC standards correlate the magnitude of average and storm wind speeds to the wind turbine class $C$, and not to a specific tower height $H$. However, a higher $H$ should incur in higher capital costs, but it should also benefit from some aerodynamic performance increase, as higher hub heights typically imply higher wind speeds because of vertical shear. To account for this, in the present work a sort of site-specific optimization is followed, where the average wind speed grows with hub height according to the wind shear power law, using a coefficient equal to 0.2 following IEC standards (International Electrotechnical Commission, 2005). On the other hand, storm winds were set following the requirements of the wind turbine class, and were therefore not updated based on hub height. Clearly, other choices are possible, and these might lead to different design solutions.

Parameters $\gamma$ and $\phi$ affect both aerodynamics and structures. The power coefficient $C_{\mathrm{P}}$ in fact typically decreases with increasing $\gamma$ and $\phi$, causing a reduction in AEP, while the maximum allowable tip deflection constraint is relaxed at growing $\gamma$ and $\phi$, leading to potential structural benefits.

Finally, the two $\sigma$ parameters are defined as rotor planar solidity $\sigma_{\mathrm{c}}$ and blade thickness solidity $\sigma_{\mathrm{t}}$, while the two $\tau$ parameters are defined as blade planar tapering $\tau_{\mathrm{c}}$ and blade thickness tapering $\tau_{\mathrm{t}}$. Their mathematical expressions are given as follows: 
$\sigma_{\mathrm{c}}=\frac{3 A_{\mathrm{b}}}{A}=\frac{3 \int_{0}^{R} c(r) \mathrm{d} r}{\pi R^{2}}$,

$\tau_{\mathrm{c}}=\frac{\int_{0}^{R} r c(r) \mathrm{d} r}{A_{\mathrm{b}}}$,

$\sigma_{\mathrm{t}}=\frac{1}{100} \int_{0}^{1} t(\eta) \mathrm{d} \eta$,

$\tau_{\mathrm{t}}=\frac{\int_{0}^{1} \eta t(\eta) \mathrm{d} \eta}{\int_{0}^{1} t(\eta) \mathrm{d} \eta}$

where $A_{\mathrm{b}}$ is the blade planar area, $A$ is the rotor swept area, $c$ is the chord, $r$ is the dimensional blade span, $t$ is the blade percentage thickness and $\eta$ is the non-dimensional blade span. The role of the four parameters $\sigma_{\mathfrak{c}}, \tau_{\mathfrak{c}}, \sigma_{\mathrm{t}}$ and $\tau_{\mathrm{t}}$ is to allow for an interaction between the aerodynamic loop of Eq. (2) and the structural loop of Eq. (4), in turn enabling an integrated rotor aero-structural design optimization. From a computational point of view, they enter as nonlinear constraints into the aerodynamic blade shape definition expressed by Eq. (2d).

Goal of the integrated optimization is to find the minimum cost $\mathrm{CoE}^{*}$ in Eq. (5b), whose computing function ComputeCoE can be expressed as

$$
\begin{aligned}
& \operatorname{Function}\left(\boldsymbol{p}_{\mathrm{a}}^{*}, \boldsymbol{p}_{\mathrm{s}}^{*}, \boldsymbol{p}_{\mathrm{g}}, \operatorname{CoE}\right)= \\
& \quad \operatorname{Compute} \operatorname{CoE}\left(\boldsymbol{p}_{\mathrm{a}}, \boldsymbol{p}_{\mathrm{s}}, \boldsymbol{p}_{\mathrm{g}}, D, \boldsymbol{\Gamma}_{\mathrm{s}}\right): \\
& \left(\boldsymbol{p}_{\mathrm{a}}^{*}, \operatorname{AEP}^{*}\right)=\operatorname{MaxAEP}\left(\boldsymbol{p}_{\mathrm{a}}, \boldsymbol{p}_{\mathrm{s}}, \boldsymbol{p}_{\mathrm{g}}, D\right), \\
& \left(\boldsymbol{p}_{\mathrm{s}}^{*}, \operatorname{ICC}^{*}\right)=\operatorname{Min} \operatorname{ICC}\left(\boldsymbol{p}_{\mathrm{a}}^{*}, \boldsymbol{p}_{\mathrm{s}}, \boldsymbol{p}_{\mathrm{g}}, D, \boldsymbol{\Gamma}_{\mathrm{s}}\right), \\
& \left(\mathrm{AEP}^{* *}\right)=\operatorname{ComputeAEP}\left(\boldsymbol{p}_{\mathrm{a}}^{*}, \boldsymbol{p}_{\mathrm{s}}^{*}, \boldsymbol{p}_{\mathrm{g}}, D\right), \\
& (\mathrm{CoE})=\operatorname{CoEmod}\left(\mathrm{AEP}^{* *}, \mathrm{ICC}^{*}, \boldsymbol{p}_{\mathrm{a}}^{*}, \boldsymbol{p}_{\mathrm{s}}^{*}, \boldsymbol{p}_{\mathrm{g}}, D\right) .
\end{aligned}
$$

The procedure is obtained by conducting in sequence an aerodynamic optimization, given in Eq. (8b); a structural optimization, given in Eq. (8c); a new calculation of the AEP considering the updated structure $\boldsymbol{p}_{\mathrm{s}}^{*}$, given in Eq. (8d); and a final evaluation of the $\mathrm{CoE}$ from the cost models, given in Eq. (8e) and later discussed in Sect. 2.3.

The outer optimization loop may also be subjected to nonlinear constraints $\boldsymbol{g}_{\mathrm{g}}$, expressed as in Eq. (5c). These may include, for example, a minimum clearance between blade tip and ground, or constraints on loads. The latter may be necessary in the presence of components that are frozen and should not be changed, for which maximum loads are given that should not be exceeded.

Overall, a graphical representation of the architecture of this preliminary-detailed design optimization procedure is shown in Fig. 2. As for the previous subproblems, even this coupled aero-structural optimization problem is solved using a SQP algorithm based on central finite differences.

To limit computational cost, the most expensive operations are parallelized. In particular, DLCs are run in parallel inde- pendently on all available cores. The same is done for the gradients in the structural loop of Eq. (4e). As no interdependency among these tasks exists, this amounts to a classical case of embarrassing parallelism, which is simply implemented by dispatching jobs on all available computational cores, and the remaining ones on the cores that become available after having completed their assigned job. As the number of design variables is relatively small, the actual solution of the optimization problem is of negligible cost (once constraints and cost function have been evaluated), and therefore it is not parallelized in the current implementation. Depending on the number of DLCs, the number of design variables, and the mesh refinement of the multibody model, the overall design process can be typically completed in a matter of hours or tens of hours.

\subsubsection{Low-induction rotor configuration}

Multi-disciplinary tools offer the opportunity of exploring alternative wind turbine designs. LIRs are one such possible solution, where the wind turbine operates on purpose at a suboptimal aerodynamic efficiency, potentially benefiting from reduced loads and consequently lighter and cheaper structures.

From an algorithmic point of view, a LIR can be designed within the current framework by means of an offset $\delta$ applied to the pitch angle, so as to feather the blade towards lower angles of attack. An alternative, possibly more sophisticated, approach would be to use a twist distribution rather than a single pitch offset. Parameter $\delta$ affects both the aerodynamics and the structure of the wind turbine, and therefore it is included in the $\boldsymbol{p}_{\mathrm{g}}$ vector of design variables:

$p_{\mathrm{g}}=\left[R, H, \gamma, \phi, \sigma_{\mathrm{c}}, \tau_{\mathrm{c}}, \sigma_{\mathrm{t}}, \tau_{\mathrm{t}}, \delta\right]$.

The use of $\delta$ results in a perturbed regulation trajectory with a lower maximum power coefficient $C_{\mathrm{P}}$ in the partial load region. This also implies lower lift and drag aerodynamic forces for wind speeds up to the rated wind velocity. The design challenge is to identify the potential optimum tradeoff between losses in aerodynamic efficiency and structural advantages in terms of ICC. The $\mathrm{CoE}$ is once again the merit figure to be monitored during this optimization.

\subsection{Cost-of-energy models}

The ultimate figure of merit for a wind turbine multidisciplinary optimization process is the CoE (Ning et al., 2013). It is therefore clear that accurate $\mathrm{CoE}$ models are of crucial importance. In fact, as the CoE drives the design, any inaccuracy in the cost model will invariably affect the design itself. In this work we have made use of the NREL cost model (Fingersh et al., 2006) and the more recent INNWIND one (INNWIND.EU, Deliverable 1.23, 2014). The main difference between the two models is the applicability range, 


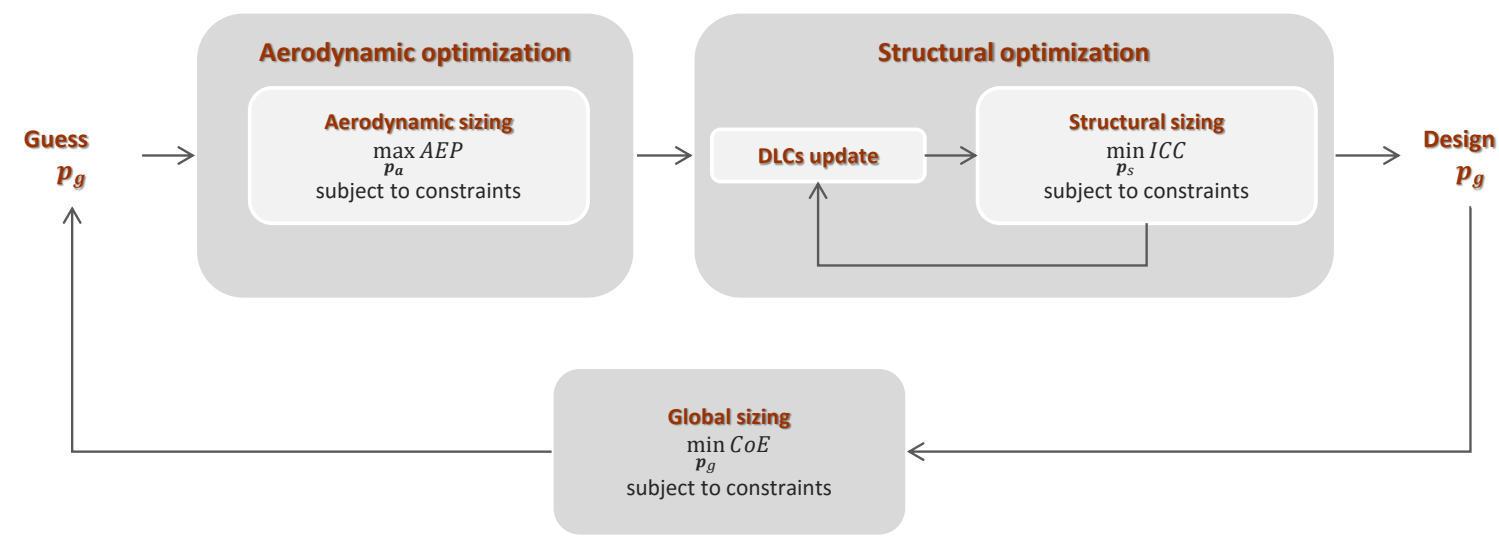

Figure 2. Architecture of the combined preliminary-detailed design procedure.

as the NREL CoE model was initially developed for midsize onshore wind turbines and only later adapted to offshore applications, while the INNWIND CoE model has been especially formulated for multi-MW next-generation offshore wind turbines.

In addition to the two CoE models, a highly detailed blade cost model (BCM) developed at Sandia National Laboratories by Johans and Griffith (2013) is also implemented in the code. This model is capable of capturing the aero-structural trade-offs of the rotor and overcomes the simplified relationships between blade mass or blade length versus blade cost used in the NREL and INNWIND CoE models. The Sandia BCM is in fact composed of three main items: material costs, labor costs and equipment costs. Material costs are estimated based on the mass of each blade structural component, differentiating between the costs of different fibers, resins, sandwich core and extra materials such as adhesive, paint, and lightning protection. Labor costs estimate the man hours needed for the manufacturing of a single blade, which are then multiplied by the wage rate, a value that can be readily tuned based for instance on the country of manufacturing. Labor hours are estimated based on reference models and several geometrical and structural scaling factors. Finally, equipment costs are estimated as price of mold and tooling divided by the number of blades that can be manufactured with a single set of equipment. The price of mold and tooling is upscaled using a power law expressed as a function of rotor radius.

Cost models are also responsible for updating all other wind turbine component costs, as well as the installation and maintenance costs. These cost items mostly scale with wind turbine macro-parameters such as rated power and rotor diameter. Notably, the recent INNWIND cost model also includes the rated rotor torque in the equations of drive train and generator system costs. This allows for the coupling between these components and the rotor design, for instance influencing the optimal rotor solidity.

\section{Applications}

The combined preliminary-detailed optimization methodology described in Sect. 2 is applied to two reference wind turbine models: a 2.2 MW wind turbine representative of current mid-size commercial-scale onshore machines, and a $10 \mathrm{MW}$ wind turbine representative of large next-generation offshore machines. The design optimization of the $2.2 \mathrm{MW}$ reference machine is presented in Sect. 3.1, while the $10 \mathrm{MW}$ wind turbine, originally developed by DTU and released in the public domain for research purposes (Bak et al., 2013) is discussed in Sect. 3.2.

\subsection{2 MW onshore wind turbine}

The 2.2 MW baseline machine is a class $3 \mathrm{~A}$ onshore threebladed wind turbine with a steel tower and a standard glassfiber-reinforced plastic (GFRP) blade configuration with two spar caps, two shear webs, a skin layer and extra unidirectional (UD) reinforcements at the leading and trailing edges. The main parameters of the wind turbine are reported in Table 1 .

Regarding aerodynamics, the blades are equipped with DU airfoils (Timmer and van Rooij, 2003) located as listed in Table 2, while the chord and twist distributions are shown in Fig. 3. The structural design, the blade topology and its structural configuration are described in Table 3 , while the material mechanical properties are listed in Table 4. In the optimization problem, the aerodynamic design parameter vector $\boldsymbol{p}_{\mathrm{a}}$ includes 13 optimization variables describing twist at five stations along blade span as well as chord and airfoil positions at four stations. The structural design parameter vector $\boldsymbol{p}_{\mathrm{s}}$ includes 34 variables parameterizing the seven structural components at nine stations along blade span. In the current study, the lay-up and fiber angles of the laminates are kept constant throughout the design optimization.

A reduced set of DLCs is selected in order to conduct the optimization design studies. Among the full set of design 

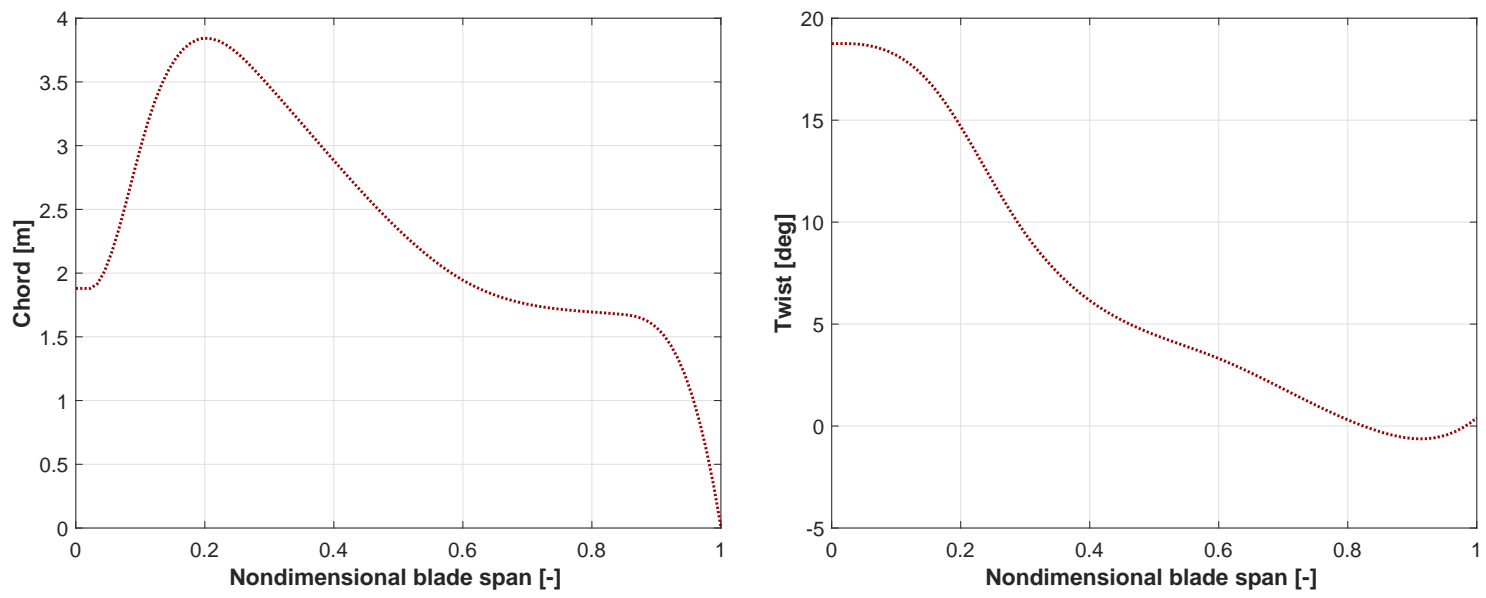

Figure 3. Baseline chord and twist distributions for the $2.2 \mathrm{MW}$ wind turbine blade.

Table 1. Configuration of the 2.2 MW onshore wind turbine.

\begin{tabular}{lr|lr}
\hline Data & Value & Data & Value \\
\hline Wind class & IEC 3A & Rated mech. power & $2.2 \mathrm{MW}$ \\
Hub height & $80.0 \mathrm{~m}$ & Rotor diameter & $92.0 \mathrm{~m}$ \\
Cut-in & $4 \mathrm{~m} \mathrm{~s}^{-1}$ & Cut-out & $25 \mathrm{~m} \mathrm{~s}^{-1}$ \\
Rotor cone & $2.0^{\circ}$ & Nacelle uptilt & $6.0^{\circ}$ \\
Rotor solidity & $4.65 \%$ & Max $V_{\text {tip }}$ & $72.0 \mathrm{~m} \mathrm{~s}^{-1}$ \\
Blade mass & $7482 \mathrm{~kg}$ & Tower mass & $119.2 \mathrm{t}$ \\
\hline
\end{tabular}

Table 2. Spanwise positioning of the airfoils for the $2.2 \mathrm{MW}$ onshore wind turbine.

\begin{tabular}{lr}
\hline Airfoil & Position \\
\hline Circle & $0.0 \%$ \\
Circle & $2.22 \%$ \\
DU00-W2-401 & $19.43 \%$ \\
DU00-W2-350 & $25.53 \%$ \\
DU97-W-300 & $35.04 \%$ \\
DU91-W2-250 & $47.69 \%$ \\
DU93-W-210 & $69.44 \%$ \\
DU95-W-180 & $89.22 \%$ \\
DU95-W-180 & $100.00 \%$ \\
\hline
\end{tabular}

conditions, DLCs 1.1, 1.2, 1.3, 2.1, 2.3 and 6.2 (International Electrotechnical Commission, 2005) were identified as those producing design drivers for the baseline wind turbine. These DLCs represent normal operating conditions, extreme turbulent wind conditions, the occurrence of extreme gusts combined with electric faults and, finally, the occurrence of a 50year storm at different values of yaw angle. To ensure that no other significant DLC had been neglected, a more complete set (International Electrotechnical Commission, 2005) of DLCs was run on the final design, indeed verifying that design driving loads were not affected. In fact, this is indeed
Table 3. Extent of the structural components and their materials for the $2.2 \mathrm{MW}$ wind turbine.

\begin{tabular}{lrrl}
\hline Component & $\begin{array}{r}\text { From } \\
\text { (\% span })\end{array}$ & $\begin{array}{r}\text { To } \\
(\% \text { span })\end{array}$ & $\begin{array}{l}\text { Material } \\
\text { type }\end{array}$ \\
\hline External shell & 0 & 100 & $\begin{array}{l}\text { Stitched triaxial } \\
-45^{\circ} / 0^{\circ} /+45^{\circ} \\
\text { fiberglass }\end{array}$ \\
\hline Spar caps & 1 & 98 & $\begin{array}{l}\text { Unidirectional } \\
\text { fiberglass }\end{array}$ \\
\hline Shear webs & 10 & 98 & $\begin{array}{l}\text { Stitched biaxial } \\
-45^{\circ} /+45^{\circ} \\
\text { fiberglass }\end{array}$ \\
\hline $\begin{array}{l}\text { Trailing and } \\
\text { leading edge } \\
\text { reinforcements }\end{array}$ & 10 & 98 & $\begin{array}{l}\text { Unidirectional } \\
\text { fiberglass }\end{array}$ \\
\hline Sandwich core & 5 & 98 & Balsa \\
\hline
\end{tabular}

a possibly effective way of reducing the computational cost: one first selects a reduced set of DLCs based on experience or on the drivers of the initial starting design, then conducts the optimization, and finally checks with a full set of DLCs, possibly repeating the design with an expanded set in case dominating DLCs are found not to have been included. Such an approach is probably in general more computationally convenient than conducting the design optimization with a truly comprehensive set of DLCs. In the present case, a further reduction in the cost of the analyses was obtained by using a single seed in the turbulent simulations, although this is typically not advisable in practical applications.

The baseline configuration is found to have active constraints for blade tip deflection during operation, resulting in a flapwise stiffness-driven blade design, active fatigue constraints for the blade shell skin, and active buckling con- 
Table 4. Summary of the material properties used in the blades of the $2.2 \mathrm{MW}$ wind turbine.

\begin{tabular}{lccr}
\hline Material type & $\begin{array}{r}\text { Longitudinal } \\
\text { Young's } \\
\text { modulus } \\
{[\mathrm{MPa}]}\end{array}$ & $\begin{array}{r}\text { Transversal } \\
\text { Young's } \\
\text { modulus } \\
{[\mathrm{MPa}]}\end{array}$ & $\begin{array}{r}\text { Shear } \\
\text { modulus }\end{array}$ \\
\hline $\begin{array}{l}\text { Stitched triaxial } \\
\text { fiberglass } \\
-45^{\circ} / 0^{\circ} /+45^{\circ}\end{array}$ & 28544 & 10280 & 6470 \\
\hline $\begin{array}{l}\text { Unidirectional } \\
\text { fiberglass }\end{array}$ & 39277 & 8450 & 3190 \\
\hline $\begin{array}{l}\text { Stitched biaxial } \\
\text { fiberglass } \\
-45^{\circ} /+45^{\circ}\end{array}$ & 9737 & 9737 & 10913 \\
\hline Balsa & 50 & 50 & 150 \\
\hline
\end{tabular}

straints for the steel tower due to storm loads. Frequency constraints for blade and tower are also active.

\subsubsection{Holistic optimization}

The baseline design of the $2.2 \mathrm{MW}$ wind turbine is used as a starting point for a full design optimization where the merit figure is the CoE calculated from the NREL cost model, while the blade cost is calculated from the Sandia BCM. Table 5 reports the initial and final values of the design parameters $\boldsymbol{p}_{\mathrm{g}}$.

The global trend of the design optimization is a clear upscale of the machine. Thanks to a larger rotor diameter and a taller hub height, a higher energy capture is indeed obtained, leading to significant advantages in terms of CoE. Cone and uptilt angles are also increased to relax the tower clearance constraint and cause the simultaneous activation of both the tip deflection and blade frequency constraints. Finally, the four blade aero-structural parameters are adjusted with respect to their baseline values to achieve an aerostructural trade-off. The rotor aerodynamic performance is indeed slightly decreased due to the aerodynamically suboptimal chord and thickness distributions shown in Fig. 4; however this limits the ICC caused by the longer blades. Minor modifications are also produced to the twist distribution on account of the different airfoil positions.

From a blade structural point of view, thicker structural elements are designed to withstand the higher loads. The distributions for spar caps, skin, webs and trailing edge reinforcement are reported in Fig. 5. Core thickness also exhibits a growth due to larger sandwich panels and higher loads. The resulting blade mass suffers a $51.6 \%$ increase. Finally, the coupled optimization of rotor and tower identifies an optimal distribution for the tower diameters in order to balance tower clearance and stiffness, to the benefit of ICC. The distributions of outer diameters and wall thicknesses along the tower
Table 5. Summary of design parameters $\boldsymbol{p}_{\mathrm{g}}$ for the holistic optimization of the $2.2 \mathrm{MW}$ onshore wind turbine.

\begin{tabular}{lrrr}
\hline Data & Reference & Optimum & Difference \\
\hline Rated mech. power & $2.2 \mathrm{MW}$ & $2.2 \mathrm{MW}$ & - \\
Rotor diameter & $92.0 \mathrm{~m}$ & $106.6 \mathrm{~m}$ & $+15.9 \%$ \\
Hub height & $80.0 \mathrm{~m}$ & $97.6 \mathrm{~m}$ & $+22.0 \%$ \\
Rotor cone & $2.0^{\circ}$ & $2.2^{\circ}$ & $+10.0 \%$ \\
Nacelle uptilt & $6.0^{\circ}$ & $6.5^{\circ}$ & $+8.3 \%$ \\
Rotor solidity $\sigma_{\mathrm{c}}$ & $4.64 \%$ & $4.26 \%$ & $-8.2 \%$ \\
Blade tapering $\tau_{\mathrm{c}}$ & 0.419 & 0.414 & $-1.2 \%$ \\
Thickness solidity $\sigma_{\mathrm{t}}$ & 0.342 & 0.348 & $+1.8 \%$ \\
Thickness tapering $\tau_{\mathrm{t}}$ & 0.344 & 0.362 & $+5.2 \%$ \\
\hline
\end{tabular}

height are shown in Fig. 6. The higher and thicker tower is heavier than the baseline by $38.7 \%$.

Overall, the optimization process leads to an increase of $16.5 \%$ in the ICC, caused by the growth of rotor, tower, drivetrain and nacelle costs, equal to $35.1,38.7$ and $10.3 \%$, respectively. The higher costs are nevertheless largely compensated for by an increase of $20.0 \%$ in the $\mathrm{AEP}$, resulting in net savings in terms of $\mathrm{CoE}$ of $3.1 \%$. It should be remarked that it would be difficult, if not impossible, to exactly quantify the effects on rotor and tower (which largely depend on their detailed sizing, accounting for all design-driving conditions) caused by changes in the macro-parameters (rotor diameter and tower height). Therefore, with a classical approach based on a preliminary design of the macro-parameters followed by a detailed design at fixed rotor diameter and tower height, it might have been harder to identify the CoE-optimal solution found here in one single shot.

The final design was obtained after only four iterations of the SQP algorithm, with a total computational time of approximately $65 \mathrm{~h}$ running on a workstation equipped with 40 logical processors.

\subsubsection{Low-induction configuration}

A second study is conducted on the $2.2 \mathrm{MW}$ onshore machine introducing the pitch offset $\delta$ within the vector of design parameters $\boldsymbol{p}_{\mathrm{g}}$ (see Eq. 9). This additional degree of freedom allows for the algorithm to choose a LI configuration (operating at lower rotor efficiency) if such a solution turns out to be further improving the figure of merit with respect to an optimal induction one. Therefore, it is important to remark that this way of approaching the problem does not force a LI solution, which will only appear if it improves the $\mathrm{CoE}$ with respect to a non-LI one.

The outcome of this problem setup results in a solution that is identical to the one of the problem discussed in Sect. 3.1.1, with an optimal $\delta$ value equal to 0 . This means that there is apparently no advantage in reducing the aerodynamic efficiency to benefit from reduced loads. In fact, savings in the 

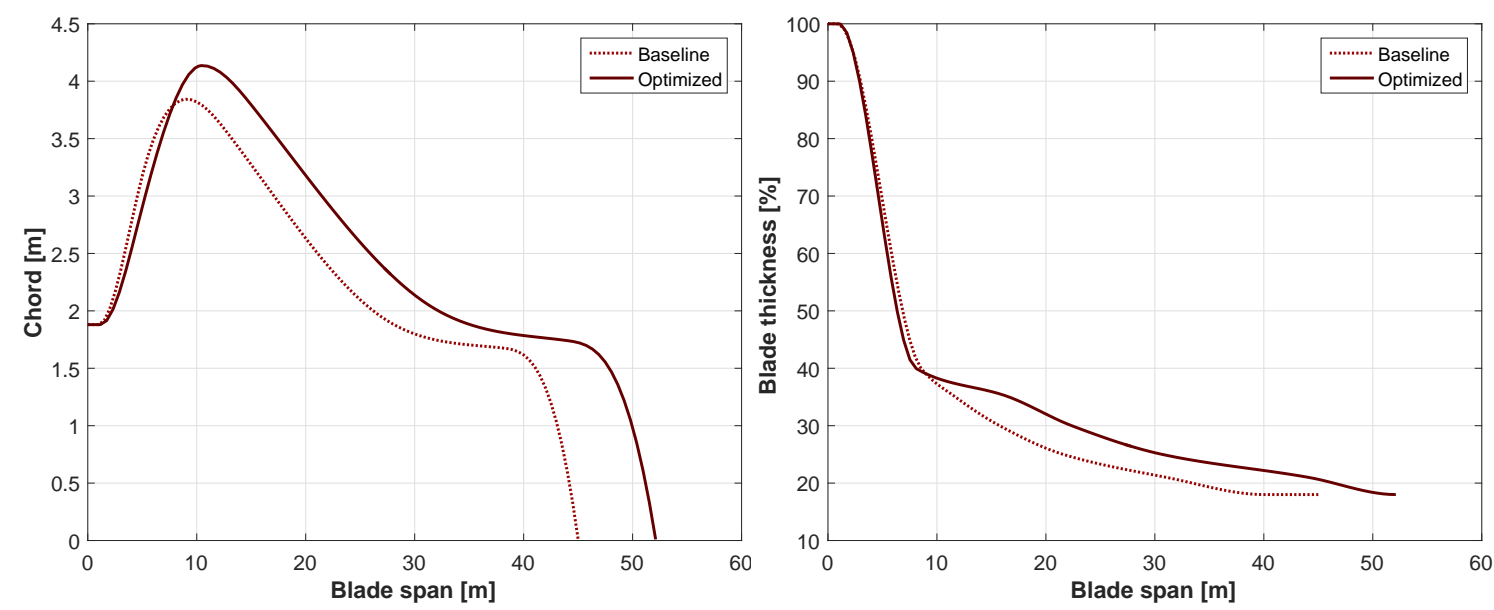

Figure 4. Chord and thickness distributions of the baseline and the optimized 2.2 MW wind turbine blades.
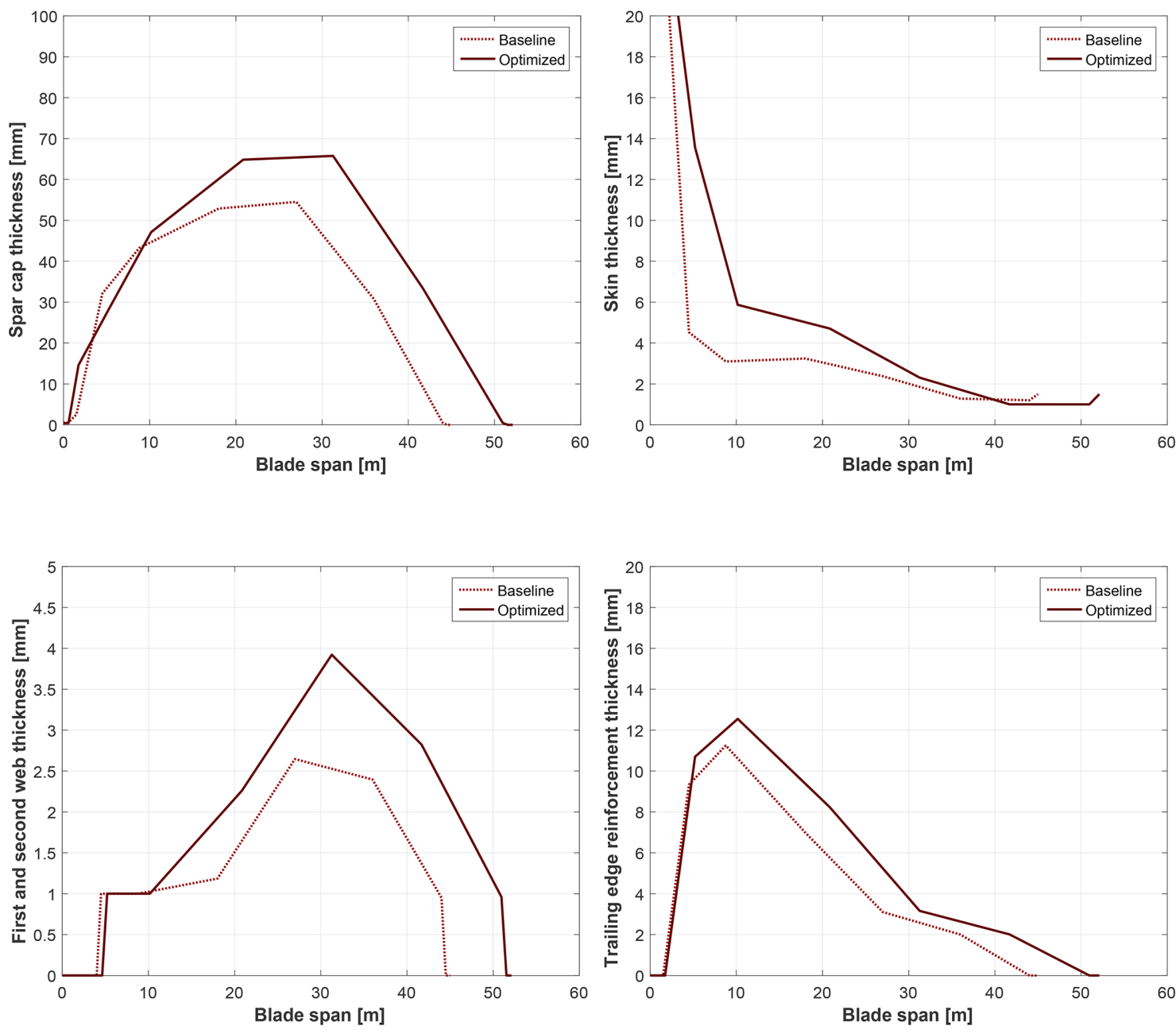

Figure 5. Structural thickness distributions of the baseline and the optimized 2.2 MW wind turbine blades. 

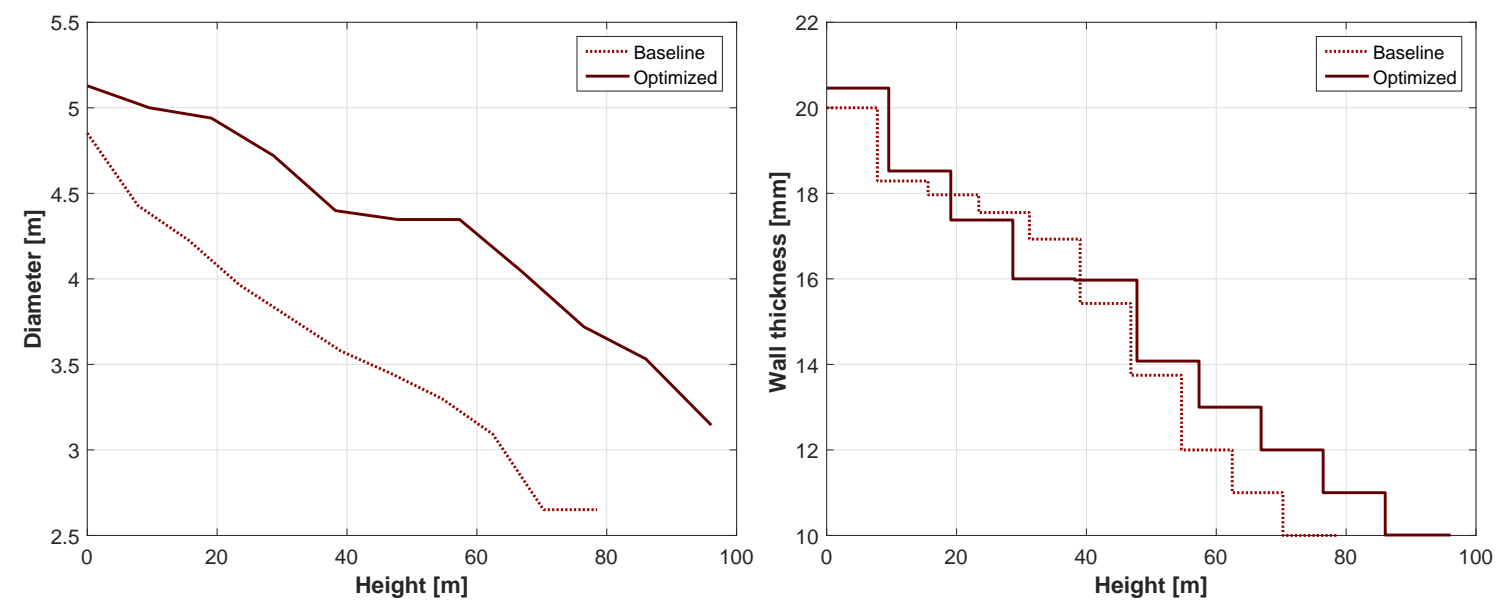

Figure 6. Tower outer diameter and wall thickness distributions of the baseline and the optimized 2.2 MW wind turbines.

latter are very limited compared to losses in the former, and the small reductions in ICC do not justify drops in the power coefficient. It is therefore concluded that a LI configuration through a pitch offset does not improve the design of this specific $2.2 \mathrm{MW}$ wind turbine.

\section{2 $10 \mathrm{MW}$ offshore wind turbine}

The proposed methodology is then exercised on the optimization of a large-scale wind turbine, representative of the next-generation offshore machines. A $10 \mathrm{MW}$ machine, developed in Bottasso et al. (2015) as an evolution of the original DTU $10 \mathrm{MW}$ reference wind turbine (RWT) (Bak et al., 2013), is chosen as a significant test case. Despite being an offshore machine, following Bak et al. (2013), no support structure is modeled here and the foundation is assumed to be a standard onshore one. The main characteristics of the wind turbine are reported in Table 6.

The reference chord and twist distributions are shown in Fig. 7, while the blades are equipped with FFA airfoils (Björck, 1990) positioned as listed in Table 7. The blade topology and the structural configuration are detailed in Table 8 , while material properties are summarized in Table 9 . The blade has a two spar caps-three webs topology, with UD composite reinforcements at the leading edge, trailing edge and in the root region. Different GFRP laminates are used in the various structural elements, while balsa wood is used as core material in the sandwich panels. The aerodynamic design vector $\boldsymbol{p}_{\mathrm{a}}$ is composed of 13 optimization variables describing twist at five stations, and chord and airfoil positioning at four stations along blade span. The structural vector $\boldsymbol{p}_{\mathrm{s}}$ is made of 69 variables parameterizing the nine structural components at 14 stations along blade span. The mechanical properties of the composites are kept fixed during the optimization process.

The same set of DLCs used for the $2.2 \mathrm{MW}$ wind turbine is adopted also in the design studies of the $10 \mathrm{MW}$ ma-
Table 6. Configuration of the $10 \mathrm{MW}$ offshore wind turbine.

\begin{tabular}{lr|lr}
\hline Data & Value & Data & Value \\
\hline Wind class & IEC 1A & Rated mech. power & $10.0 \mathrm{MW}$ \\
Hub height & $119.0 \mathrm{~m}$ & Rotor diameter & $178.3 \mathrm{~m}$ \\
Cut-in & $4 \mathrm{~m} \mathrm{~s}^{-1}$ & Cut-out & $25 \mathrm{~m} \mathrm{~s}^{-1}$ \\
Rotor cone & $4.65^{\circ}$ & Nacelle uptilt & $5.0^{\circ}$ \\
Rotor solidity & $4.66 \%$ & Max $V_{\text {tip }}$ & $90.0 \mathrm{~m} \mathrm{~s}^{-1}$ \\
Blade mass & $42496 \mathrm{~kg}$ & Tower mass & $628.0 \mathrm{t}$ \\
\hline
\end{tabular}

Table 7. Spanwise positioning of the airfoils for the $10 \mathrm{MW}$ wind turbine.

\begin{tabular}{lr}
\hline Airfoil & Position \\
\hline Circle & $0.0 \%$ \\
Circle & $1.74 \%$ \\
FFA-W3-480 & $20.80 \%$ \\
FFA-W3-360 & $29.24 \%$ \\
FFA-W3-301 & $38.76 \%$ \\
FFA-W3-241 & $71.87 \%$ \\
FFA-W3-241 & $100.00 \%$ \\
\hline
\end{tabular}

chine (INNWIND.EU, Deliverable 2.22, 2015), while wind conditions are adjusted for its different class following IEC certification guidelines (International Electrotechnical Commission, 2005). Specifically, the average wind speed at a hub height of $119 \mathrm{~m}$ is assumed to be $10 \mathrm{~m} \mathrm{~s}^{-1}$, while the 50 -year storm wind speed is set to $50 \mathrm{~m} \mathrm{~s}^{-1}$. The $10 \mathrm{MW}$ reference rotor is found to be highly tip-deflection-driven, with the blade flap frequency constraint largely satisfied. Moreover, the ratio of edge to flap blade frequencies, imposed to be higher than 1.1 in order to prevent mode coalescence, drives the edgewise stiffness, and in turn the design of trailing and leading edge reinforcements. Finally, blade 

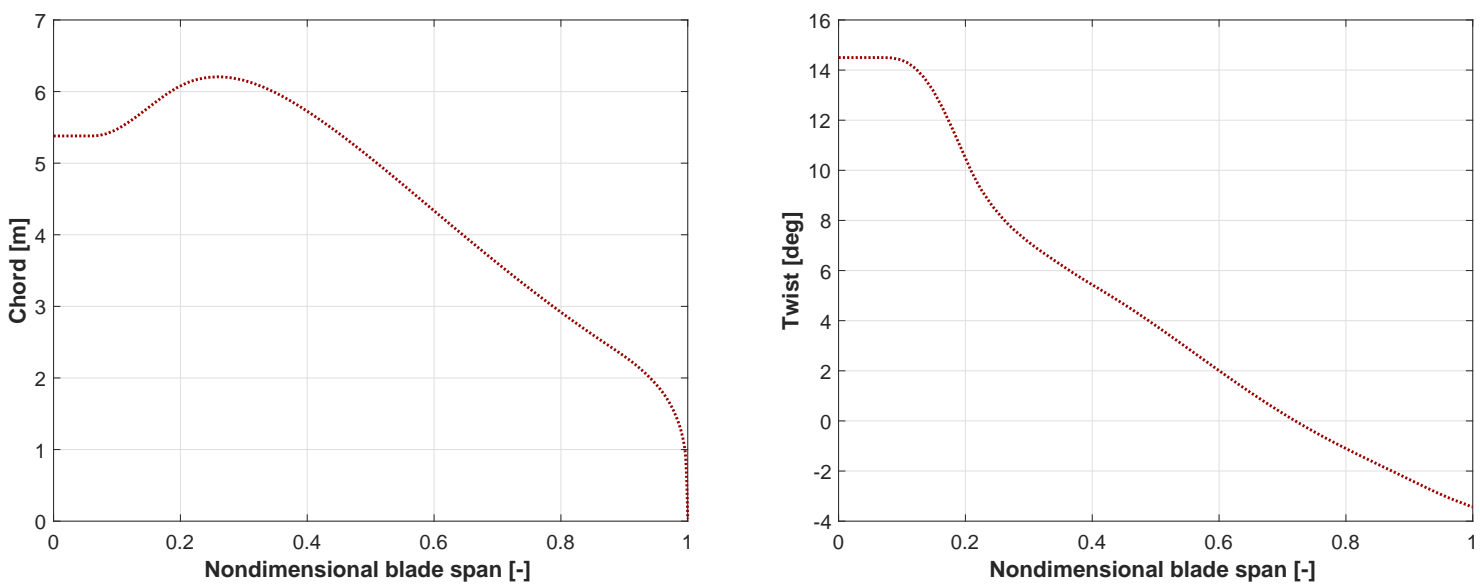

Figure 7. Baseline chord and twist distribution for the $10 \mathrm{MW}$ wind turbine blade.

Table 8. Extent of the structural components and their materials for the $10 \mathrm{MW}$ wind turbine.

\begin{tabular}{lrrl}
\hline Component & $\begin{array}{r}\text { From } \\
\text { \% span })\end{array}$ & $\begin{array}{r}\text { To } \\
\text { (\% span) }\end{array}$ & $\begin{array}{l}\text { Material } \\
\text { type }\end{array}$ \\
\hline External shell & 0 & 100 & $\begin{array}{l}\text { Stitched triaxial } \\
-45^{\circ} / 0^{\circ} /+45^{\circ} \\
\text { fiberglass }\end{array}$ \\
\hline Spar caps & 1 & 99.8 & $\begin{array}{l}\text { Unidirectional } \\
\text { fiberglass }\end{array}$ \\
\hline Shear webs & 5 & 99.8 & $\begin{array}{l}\text { Stitched biaxial } \\
-45^{\circ} /+45^{\circ} \\
\text { fiberglass }\end{array}$ \\
\hline $\begin{array}{l}\text { Third } \\
\text { shear } \\
\text { web }\end{array}$ & 22 & 95 & $\begin{array}{l}\text { Stitched biaxial } \\
-45^{\circ} /+45^{\circ} \\
\text { fiberglass }\end{array}$ \\
\hline $\begin{array}{l}\text { Trailing and } \\
\text { leading edge } \\
\text { reinforcements }\end{array}$ & 10 & 95 & $\begin{array}{l}\text { Unidirectional } \\
\text { fiberglass }\end{array}$ \\
\hline $\begin{array}{l}\text { Root } \\
\text { reinforcement }\end{array}$ & 0 & 22 & $\begin{array}{l}\text { Unidirectional } \\
\text { fiberglass }\end{array}$ \\
\hline $\begin{array}{l}\text { Shell core } \\
\text { Web core }\end{array}$ & 5 & 99.8 & Balsa \\
\hline
\end{tabular}

skin is again fatigue-driven, while tower structure is designed against buckling caused by storm loads.

\subsubsection{Holistic optimization}

The reference design of the $10 \mathrm{MW}$ offshore wind turbine is used as an initial starting guess for a combined preliminarydetailed optimization study. The merit figure is the CoE computed from a combination of the INNWIND and Sandia cost models. Overall, the proposed holistic approach identifies
Table 9. Summary of the material properties used in the blades of the $10 \mathrm{MW}$ wind turbine.

\begin{tabular}{lrrr}
\hline Material type & $\begin{array}{r}\text { Longitudinal } \\
\text { Young's } \\
\text { modulus } \\
{[\mathrm{MPa}]}\end{array}$ & $\begin{array}{r}\text { Transversal } \\
\text { Young's } \\
\text { modulus } \\
{[\mathrm{MPa}]}\end{array}$ & $\begin{array}{r}\text { Shear } \\
\text { modulus } \\
{[\mathrm{MPa}]}\end{array}$ \\
\hline $\begin{array}{l}\text { Stitched triaxial } \\
-45^{\circ} / 0^{\circ} /+45^{\circ} \\
\text { fiberglass }\end{array}$ & 21790 & 14670 & 9413 \\
\hline $\begin{array}{l}\text { Unidirectional } \\
\text { fiberglass }\end{array}$ & 41630 & 14930 & 5047 \\
\hline $\begin{array}{l}\text { Stitched biaxial } \\
-45^{\circ} /+45^{\circ}\end{array}$ & 13920 & 13920 & 11500 \\
fiberglass & 50 & 50 & 150 \\
\hline Balsa & & & \\
\hline
\end{tabular}

significant CoE margins by upscaling the rotor diameter and hub height. The final rotor design has both the blade frequency and maximum allowable tip deflection constraints that are active at convergence. This results from the combined detailed sizing of rotor and tower, together with the adjustment of rotor cone angle and nacelle uptilt.

A comparison of the elements of the vector of design parameters $\boldsymbol{p}_{\mathrm{g}}$ is shown in Table 10.

In terms of the blade aero-structural parameters, only the chord distribution is adjusted towards a lower rotor solidity, as shown in Fig. 8, while the airfoil positions remain essentially the same. A check is performed running a new optimization from a perturbed initial guess and very similar results are obtained in terms of blade thickness distribution. The twist also undergoes changes, particularly in the tip region, which in the end cause small aerodynamic improvements in terms of $C_{\mathrm{P}}$. The twist distribution might benefit from a refinement performed with a higher-fidelity aerody- 

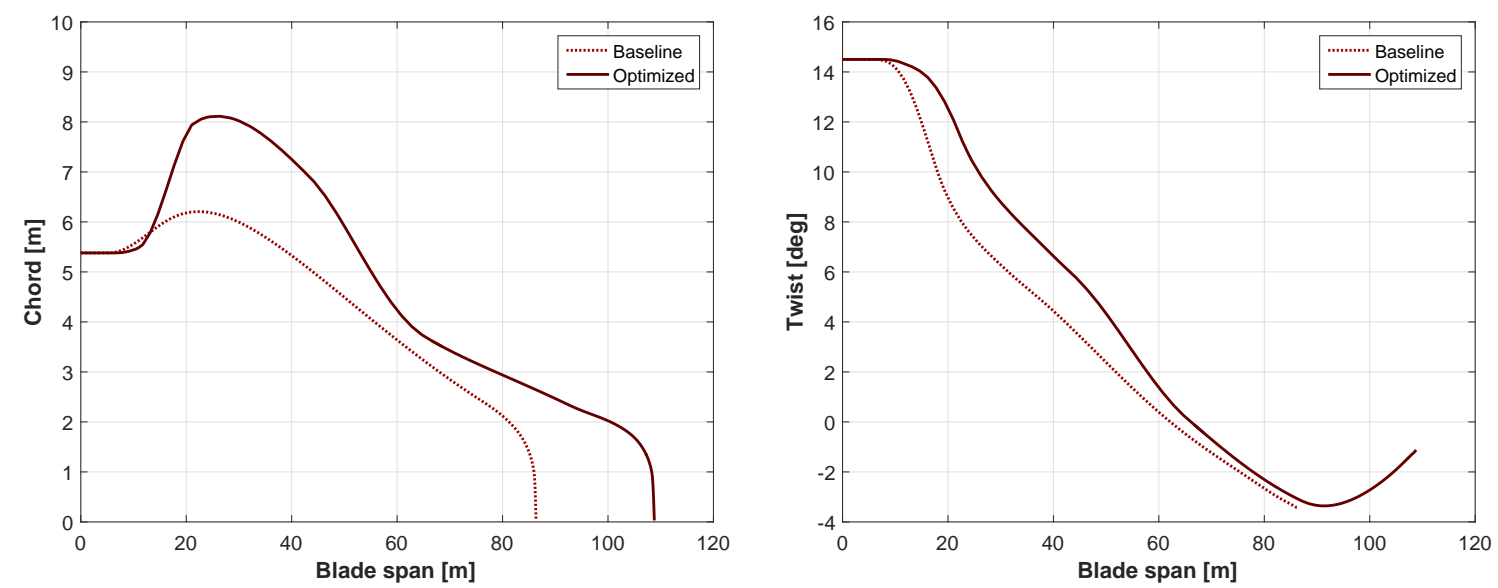

Figure 8. Chord and twist distributions of the baseline and the optimized $10 \mathrm{MW}$ wind turbine blades.

Table 10. Summary of design parameters $\boldsymbol{p}_{\mathrm{g}}$ for the holistic optimization of the $10 \mathrm{MW}$ onshore wind turbine.

\begin{tabular}{lrrr}
\hline Data & Reference & Optimum & Difference \\
\hline Rated mech. power & $10 \mathrm{MW}$ & $10 \mathrm{MW}$ & - \\
Rotor diameter & $178.3 \mathrm{~m}$ & $223.2 \mathrm{~m}$ & $+25.2 \%$ \\
Hub height & $119.0 \mathrm{~m}$ & $138.3 \mathrm{~m}$ & $+16.2 \%$ \\
Rotor cone & $4.65^{\circ}$ & $5.51^{\circ}$ & $+18.54 \%$ \\
Nacelle uptilt & $5.00^{\circ}$ & $5.25^{\circ}$ & $+5.0 \%$ \\
Rotor solidity $\sigma_{\mathrm{c}}$ & $4.66 \%$ & $4.08 \%$ & $-12.4 \%$ \\
Blade tapering $\tau_{\mathrm{c}}$ & 0.429 & 0.406 & $-5.4 \%$ \\
Thickness solidity $\sigma_{\mathrm{t}}$ & 0.389 & 0.389 & $+0.0 \%$ \\
Thickness tapering $\tau_{\mathrm{t}}$ & 0.358 & 0.358 & $+0.0 \%$ \\
\hline
\end{tabular}

namic model, which will be the subject of future work. As shown in Fig. 9, the structure of the optimal blade also undergoes a large upscaling, particularly in the spar caps. Manufacturing constraints to limit the thickness of these structural elements are available in the code but were not used in the present exercise. Overall, the blade mass experiences a $77.9 \%$ growth.

The tower also undergoes a significant upscaling, both due to aerodynamic advantages implied by a higher hub height and because of the need to resist the higher loads produced by a larger rotor. The comparison between reference and optimal tower structures is shown in Fig. 10.

It is interesting to note that the monolithic structural optimization of rotor and tower structures performed by function MinICC (see Eq. 4) finds a solution that shows a noticeable interaction between these two components. This is well visible on the left diagram in Fig. 10, where the distribution of outer diameters shows a step behavior, whose effect is to increase the clearance between tower and blade tip. The algorithm is then able to reduce blade mass thanks to the relaxation of the tip deflection constraint, which results in savings in ICC. Note that it is not a standard practice to simultane- ously optimize rotor and tower, while apparently this might lead to savings due to the correct consideration of the mutual effects of the two components. Overall, tower height moves from 115.6 to $134.9 \mathrm{~m}$, with a tower mass increase of $43.5 \%$.

A cost analysis of the combined preliminary-detailed optimization process shows a significant growth of the ICC, equal to $14.3 \%$. This results from a growth of $34.0 \%$ of the rotor costs, of $29.5 \%$ of the drivetrain and nacelle costs, and of $43.5 \%$ of the tower costs. However, the associated massive growth of the AEP, which passes from 48.8 to $57.2 \mathrm{GWh}$, largely justifies the higher investment costs, resulting in a CoE reduction of $7.0 \%$.

Clearly, these design solutions are highly cost-modeldependent and different relationships for expenses related to transportation, logistics or other items may lead to very different conclusions as to what is the actual optimal configuration. This should once again highlight the need for physicsbased high-quality cost models, an area of investigation that should probably be developed further, as relatively little is available in the public domain.

The computational cost of the design optimization for the $10 \mathrm{MW}$ wind turbine was larger than the one of the $2.2 \mathrm{MW}$, possibly due to an initial guess farther away from the optimum. The final design was found in six iterations of the SQP algorithm, with a total computational time of approximately $100 \mathrm{~h}$ on a workstation equipped with 40 logical processors.

\subsubsection{Low-induction configuration}

A LI configuration is also investigated for the offshore $10 \mathrm{MW}$ machine, using the same methodological approach used for the 2.2 MW case. Even in this case, a holistic optimization returned a traditional non-LI design.

To further investigate the concept, in a second attempt unexceedable loads from the blade root down to the rest of the wind turbine structure were assumed. Such a design solution could indeed be attractive in the context of a partial redesign 

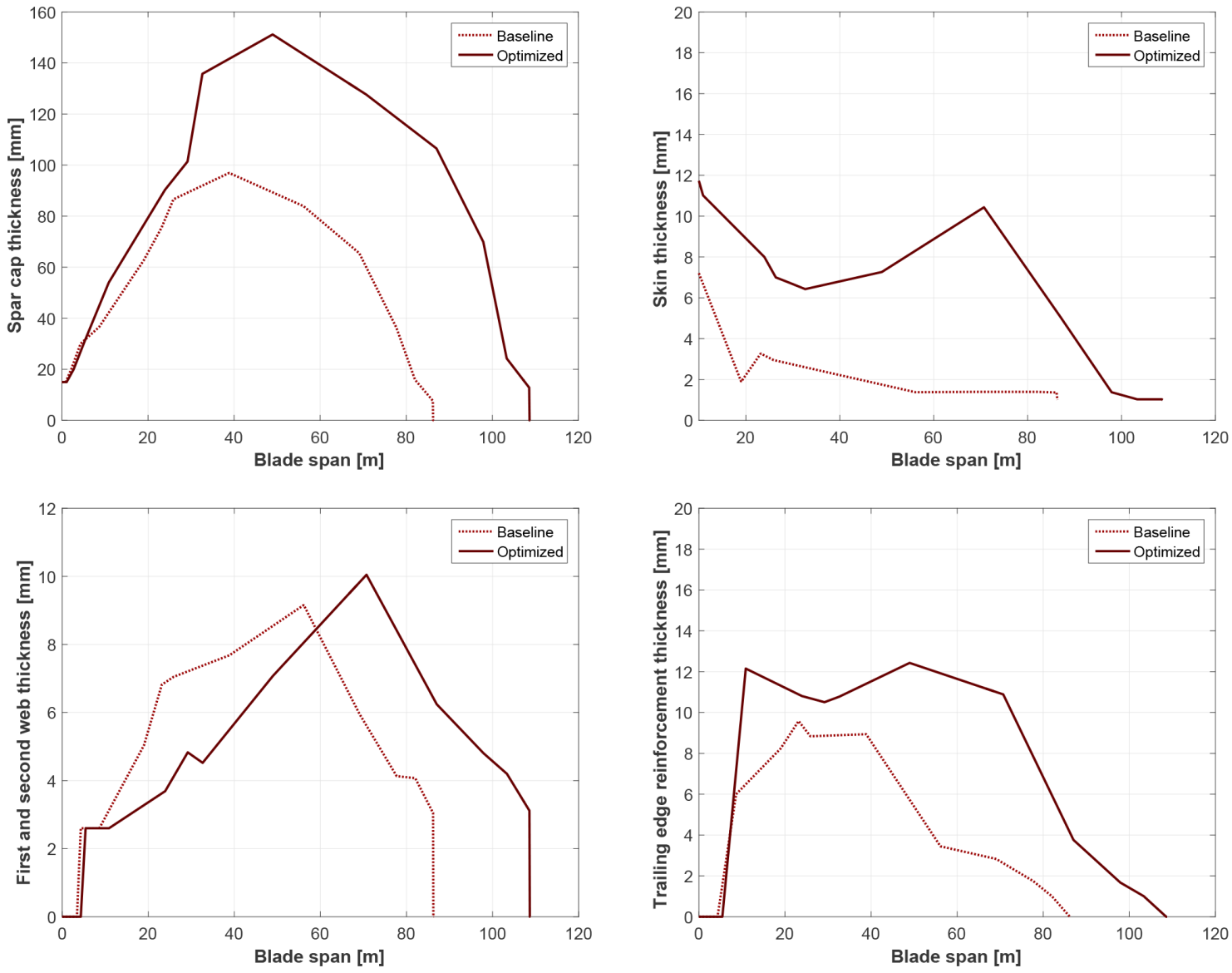

Figure 9. Structural thickness distributions of the baseline and the optimized $10 \mathrm{MW}$ wind turbine blades.
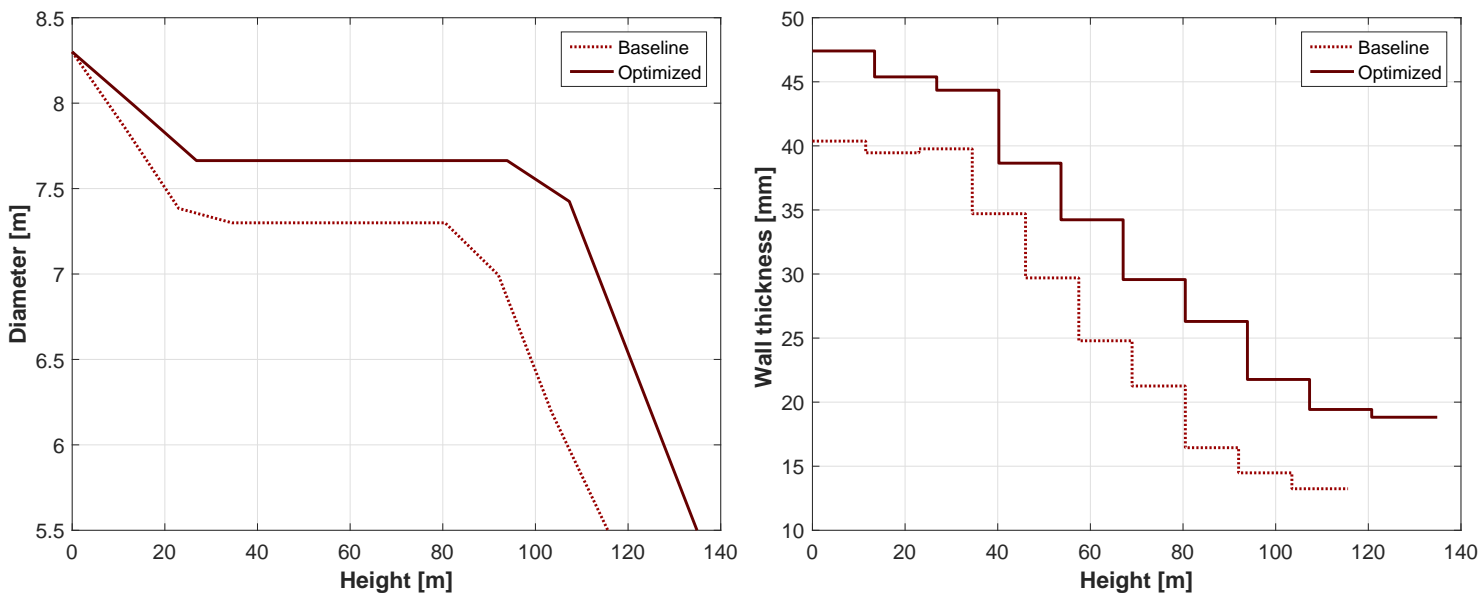

Figure 10. Tower outer diameter and wall thickness distributions of the baseline and the optimized $10 \mathrm{MW}$ wind turbines.

effort, such as a reblading of the rotor, whereas a full redesign would require massive changes in terms of technologies, supply chain, manufacturing processes, logistics, etc. In such a situation, one could try to improve the CoE by increasing the rotor radius, while at the same time not exceeding some of the loads of the baseline machine. This approach is performed with the proposed methodology by assuming a frozen wind turbine configuration except for the rotor radius, with $\boldsymbol{p}_{\mathrm{g}}$ that reduces in this case to the following:

$$
\boldsymbol{p}_{\mathrm{g}_{\mathrm{LIR}}}=[R, \delta] \text {. }
$$


The baseline values for rotor thrust and blade root combined moment are selected as constraints for this partial redesign effort. Although other choices are indeed possible, such a simple solution somewhat translates the requirements of not exceeding the baseline loads in the rest of the machine. Under these conditions, an optimal LIR design is found at a rotor diameter of $188.5 \mathrm{~m}$, corresponding to a growth of $5.7 \%$ compared to the baseline design, and a pitch offset of $2.1^{\circ}$. The rotor shows a drop in $C_{\mathrm{P}}$ equal to $-0.4 \%$, but an increase in AEP thanks to the larger rotor swept area of $2.8 \%$. Overall, savings of about $2.0 \%$ are found in the CoE.

The main drawback of such an approach is that only loads that come from operational conditions in region II can be constrained in a LIR, while storm, shutdown or loads generated in region III are not influenced by $\delta$ and may require a more careful assessment (Bottasso et al., 2014b). Table 11 reports a summary of the load analysis, indicating that some important loads do indeed come from conditions that are not affected by a LI design. In conclusions, the LIR configuration found this way may be attractive but only when a lower induction can indeed reduce all driving loads in all components, a condition that is seldom, if ever, verified.

\section{Conclusions}

This paper has presented integrated design methodologies for wind turbines that marry preliminary and detailed design procedures. The proposed algorithmic process aims at a minimization of the $\mathrm{CoE}$ merit figure at constant rated power. This is obtained by a novel procedure that stacks in sequence a rotor aerodynamic optimization for maximum AEP and a monolithic rotor and tower structural optimization for minimum ICC. An external loop optimizes rotor radius, hub height, rotor cone angle, nacelle uptilt angle and the blade aero-structural configuration. Next, an aerodynamic sub-loop optimizes chord, twist and thickness distributions for a given choice of airfoils and for given aero-structural constraints on rotor shape. Lastly, a structural sub-loop identifies the optimal thickness distributions of the blade structural components, such as shell skin, spar caps, webs and reinforcements, and the optimal distributions of diameter and wall thickness along the tower. Although broken down into sequential steps, the overall iterative procedure results in an integrated algorithm, where changes in any one discipline (aerodynamics, structures, controls) influences the others. The output of the procedure is the optimized design of a wind turbine, including details on blade shape, blade structure, tower structure, control parameters, load envelopes at all verification stations, and costs of the various components.

This novel design methodology is applied to two reference wind turbine designs: a commercial-scale 2.2 MW onshore machine and a conceptual next-generation $10 \mathrm{MW}$ offshore wind turbine. In the first case, the machine is found to be slightly undersized in terms of rotor radius and hub
Table 11. Summary of load analysis for the LIR design of the $10 \mathrm{MW}$ onshore wind turbine (YM: yaw misalignment).

\begin{tabular}{|c|c|c|c|}
\hline Load & $\begin{array}{r}\text { Driving DLC } \\
\text { baseline }\end{array}$ & $\begin{array}{r}\text { Driving DLC } \\
\text { optimum }\end{array}$ & $\begin{array}{r}\text { Load } \\
\text { difference }\end{array}$ \\
\hline $\begin{array}{l}\text { Blade root } \\
\text { combined } \\
\text { moment }\end{array}$ & $\begin{array}{r}\text { DLC13 } \\
\text { at } 13 \mathrm{~m} \mathrm{~s}^{-1}\end{array}$ & $\begin{array}{r}\text { DLC13 } \\
\text { at } 13 \mathrm{~m} \mathrm{~s}^{-1}\end{array}$ & $-0.3 \%$ \\
\hline $\begin{array}{l}\text { Blade root } \\
\text { torsional } \\
\text { moment }\end{array}$ & $\begin{array}{r}\text { DLC62 } \\
\text { at } 30^{\circ}(\mathrm{YM})\end{array}$ & $\begin{array}{r}\text { DLC62 } \\
\text { at } 30^{\circ} \mathrm{YM}\end{array}$ & $+1.8 \%$ \\
\hline $\begin{array}{l}\text { Rotor } \\
\text { thrust }\end{array}$ & $\begin{array}{r}\text { DLC13 } \\
\text { at } 13 \mathrm{~m} \mathrm{~s}^{-1}\end{array}$ & $\begin{array}{r}\text { DLC13 } \\
\text { at } 13 \mathrm{~m} \mathrm{~s}^{-1}\end{array}$ & $-5.2 \%$ \\
\hline $\begin{array}{l}\text { Tower base } \\
\text { combined } \\
\text { moment }\end{array}$ & $\begin{array}{r}\text { DLC62 } \\
\text { at }-30^{\circ} \mathrm{YM}\end{array}$ & $\begin{array}{r}\text { DLC62 } \\
\text { at } 60^{\circ} \mathrm{YM}\end{array}$ & $+14.8 \%$ \\
\hline $\begin{array}{l}\text { Hub } \\
\text { overturning } \\
\text { moment }\end{array}$ & $\begin{array}{r}\text { DLC13 } \\
\text { at } 23 \mathrm{~m} \mathrm{~s}^{-1}\end{array}$ & $\begin{array}{r}\text { DLC13 } \\
\text { at } 25 \mathrm{~m} \mathrm{~s}^{-1}\end{array}$ & $+18.0 \%$ \\
\hline $\begin{array}{l}\text { Yaw bearing } \\
\text { moment }\end{array}$ & $\begin{array}{r}\text { DLC13 } \\
\text { at } 17 \mathrm{~m} \mathrm{~s}^{-1}\end{array}$ & $\begin{array}{r}\text { DLC62 } \\
\text { at } 60^{\circ} \mathrm{YM}\end{array}$ & $+21.9 \%$ \\
\hline
\end{tabular}

height. Moreover, the blade aero-structural configuration is altered by increasing chord and thickness distributions. Improvements in the wind turbine design jointly improve the cost of the machine and the AEP, resulting in a CoE reduction of $3.1 \%$. The redesign of the $10 \mathrm{MW}$ wind turbine leads to more pronounced advantages in terms of $\mathrm{CoE}$, as the size of the reference baseline machine is found to be significantly smaller than the optimum identified by the proposed procedures. Despite a massive increase in ICC, the larger rotor swept area and the higher average wind speed lead to a higher AEP that more than offsets the increase in cost, in turn leading to a $\mathrm{CoE}$ reduction of about $7.0 \%$.

Overall, significant design changes are obtained for wind turbines that were already considered as very reasonable solutions. The new optima are identified in a completely automatic manner by the integration of the preliminary-designlevel macro-parameters with detailed-design-level structural and aerodynamics variables. In addition, the monolithic optimization of rotor and tower, together with rotor cone and uptilt, is capable of finding best-compromise solutions through the couplings induced by the blade tip clearance constraint. Finally, thanks to the level of fidelity of the simulation and verification models used within this framework, results are expected to be close to industrial products. Higher-fidelity aerodynamic tools could be used to improve the design beyond what is possible with BEM-like methods such as the one used here, for example by refining the tip and root regions by first-principle computational fluid dynamics (CFD) approaches. 
In addition to the full design optimization, in this study LIR configurations are investigated to evaluate the potential benefits of a reduced induction coefficient and the potentially reduced associated loads. This capability is obtained by introducing an offset design variable to the rated pitch angle. The cases considered in the presented study show that LIR solutions do not appear to be optimal, as standard optimal efficiency rotors appear to be in general associated with lower values of CoE. LIR optimal solutions were only obtained when constraining maximum loads on wind turbine components other than the blades. However, such a result may only appear for machines that are not driven by loads generated during storms, shutdowns or other conditions when low induction does not help.

Ongoing work is proceeding on various fronts to further improve the methods by increasing their generality and level of sophistication. Among the various features under investigation, we mention here the ability to perform multiobjective and/or Pareto front optimizations, which are useful for generating a family of optimal solutions instead of single points, as well as probabilistic optimization methods that can take into account uncertainties in data, operating conditions and models.

Acknowledgement. The present work is partially supported at the Politecnico di Milano by the EU FP7 INNWIND project. The authors acknowledge D. T. Griffith of Sandia National Laboratories for making available the Sandia BCM.

Edited by: M. Muskulus

\section{References}

Ashuri, T., Zaaijer, M. B., Martins, J. R. R. A., van Bussel, G. J. W., and van Kuik, G. A. M.: Multidisciplinary design optimization of offshore wind turbines for minimum levelized cost of energy, Renew. Energ., 68, 893-905 doi:10.1016/j.renene.2014.02.045, 2014.

Bak, C., Zahle, F., Bitsche, R., Kim, T., Yde, A., Henriksen, L. C., Andersen, P. B., Natarajan, A., and Hansen, M. H.: Description of the DTU $10 \mathrm{MW}$ reference wind turbine, DTU Wind Energy Report-I-0092, July, 2013.

Bauchau, O. A., Epple, A., and Bottasso, C. L.: Scaling of constraints and augmented Lagrangian formulations in multibody dynamics simulations, J. Comput. Nonlin. Dyn., 4, 021007, doi:10.1115/1.3079826, 2009.

Bauchau, O. A., Bottasso, C. L., and Trainelli, L.: Robust integration schemes for flexible multibody systems, Comput. Meth. Appl. Mech. Eng., 192, 395-420, doi:10.1016/S00457825(02)00519-4, 2003.

Bauchau, O. A.: Flexible Multibody Dynamics, in: Solid Mechanics and its Applications, Springer Netherlands, ISBN:978-94-0070334-6, 2011.

Björck, A.: Coordinates and calculations for the FFA-W1-xxx, FFA-W2-xxx and FFA-W3-xxx series of airfoils for horizontal axis wind turbines, FFA TN 1990-15, The Aeronautical Research Institute of Sweden, Stockholm, 1990.

Bottasso, C. L., Croce, A., Savini, B., Sirchi, W., and Trainelli, L.: Aero-servo-elastic modeling and control of wind turbines using finite-element multibody procedures, Multibody Syst. Dyn., 16, 291-308, doi:10.1007/s11044-006-9027-1, 2006.

Bottasso, C. L., Campagnolo, F., and Croce, A.: Multi-disciplinary constrained optimization of wind turbines, Multibody Syst. Dyn., 27, 21-53, doi:10.1007/s11044-011-9271-x, 2011.

Bottasso, C. L., Croce, A., Nam, Y., and Riboldi, C. E. D.: Power curve tracking in the presence of a tip speed constraint, Renew. Energ., 40, 1-12, doi:10.1016/j.renene.2011.07.045, 2012.

Bottasso, C. L., Campagnolo, F., and Tibaldi, C.: Optimizationbased study of bend-twist coupled rotor blades for passive and integrated passive/active load alleviation, Wind Energy, 16, 11491166, doi:10.1002/we.1543, 2013.

Bottasso, C. L., Campagnolo, F., Croce, A., Dilli, S., Gualdoni, F., and Nielsen, M. B.: Structural optimization of wind turbine rotor blades by multi-level sectional/multibody/3-D-FEM analysis, Multibody Syst. Dyn., 32, 87-116, doi:10.1007/s11044-0139394-3, 2014.

Bottasso, C. L., Croce, A., and Riboldi, C. E. D.: Optimal shutdown management, J. Phys.: Conf. Ser., 524, 012050, doi:10.1088/1742-6596/524/1/012050, 2014.

Bottasso, C. L., Bortolotti, P., Croce, A., and Gualdoni, F.: Integrated aero-structural optimization of wind turbine rotors, Multibody Syst. Dyn., doi:10.1007/s11044-015-9488-1, online first, 2015.

Chaviaropoulos, P. K. and Sieros G.: Design of Low Induction Rotors for use in large offshore wind farms, EWEA 2014 Conference, 10-13 March 2014, Barcelona, Spain, 2014.

Døssing, M.: Optimization of wind turbine rotors - using advanced aerodynamic and aeroelastic models and numerical optimization, Risø-PhD-69(EN), 2011

Duineveld, N. P.: Structure and possibilities of the FOCUS design package, Dutch Wind Workshops, TU Delft, Delft, the Netherlands, 2008.

Dykes, K., Ning, A., King, R., Graf, P., Scott, G., and Veers, P.: Sensitivity analysis of wind plant performance to key turbine design parameters: a systems engineering approach, NREL/CP5000-60920, 2014.

Fingersh, L., Hand, M., and Laxson, A.: Wind turbine design cost and scaling model, Technical Report NREL/TP-500-40566, 2006.

Germanischer Lloyd (GL): Guideline for the Certification of Wind Turbines, Ed. 2010, Germanischer Lloyd Industrial Services GmbH, Renewables Certification, Brooktorkai 10, 20457 Hamburg, Germany, 2010.

Giavotto, V., Borri, M., Mantegazza, P., and Ghiringhelli, G.: Anisotropic beam theory and applications, Comput. Struct. 16 , 403-413, doi:10.1016/0045-7949(83)90179-7,1983.

INNWIND.EU: Deliverable 1.23, PI-based assessment of innovative concepts (methodology), INNWIND.EU technical report, Deliverable 1.23, available at: www.innwind.eu, April 2014.

INNWIND.EU: Deliverable 2.22, New lightweight structural blade designs and blade designs with build-in structural couplings, INNWIND.EU technical report, Deliverable 2.22, available at: www.innwind.eu, October 2015. 
International Electrotechnical Commission: IEC 61400-1, Wind Turbines - Part 1: Design Requirements, Edn. 3., International Standard, International Electrotechnical Commission, 2005.

Johans, W. and Griffith, D. T.: Large Blade Manufacturing Cost Studies Using the Sandia Blade Manufacturing Cost Tool and Sandia 100-meter Blades, Sandia National Laboratories, Tech. Rep., 2013.

Jonkman, B. J. and Kilcher, L.: TurbSim User's Guide: Version 1.06.00, NREL Technical Report, September 2012.

Jureczko, M., Pawlak, M., and Mężyk, A.: Optimisation of wind turbine blades, J. Mater. Process. Tech., 167, 463-471, doi:10.1016/j.jmatprotec.2005.06.055, 2005.

Maalawi, K. Y. and Badr, M. A.: A practical approach for selecting optimum wind rotors, Renew. Energ., 28, 803-822, doi:10.1016/S0960-1481(02)00028-9, 2003.

Maki, K., Sbragio, R., and Vlahopoulos, N.: System design of a wind turbine using a multi-level optimization, Renew. Energ., 43, 101-110, doi:10.1016/j.renene.2011.11.027, 2012.
MSC Software: MSC NASTRAN 2012 Quick Reference Guide, MSC Software, 2012.

Ning, A., Damiani, R., and Moriarty, P. J.: Objectives and constraints for wind turbine optimization, 51st AIAA Conference, Grapevine, Texas, USA, 7-10 January 2013, doi:10.2514/6.2013-201, 2013.

Raymer, D. P.: Aircraft Design: A Conceptual Approach, AIAA Education Series, 5th Edn., Reston, VA, USA, 2012.

Roskam J.: Airplane Design - Parts I through VII (v. 1-7), Darcorporation, Lawrence, KS, USA, 2nd edition, ISBN 1884885241, 2003.

Timmer, N. and van Rooij, R. P. J. O. M.: Summary of the Delft University wind turbine dedicated airfoils, J. Sol. Energ.-T. ASME, 125, 488-496, doi:10.1115/1.1626129, 2003.

Xudong, W., Shen, W. Z., Zhu, W. J., Sørensen, J. N., and Jin, C.: Shape optimization of wind turbine blades, Wind Energy, 12, 781-803, doi:10.1002/we.335, 2009. 